\title{
Fiscal Multipliers in Brazil: A Sensitivity Analysis on the Structural Identification Procedure
}

\author{
Gilberto da Silveira Barros, Fernando Motta Correia* \\ Department of Economics, Federal University of Paraná, Curitiba, Brazil \\ Email: gilsbn@gmail.com, ^fmottabr@yahoo.com.br
}

How to cite this paper: Barros, G.S., and Correia, F.M. (2019) Fiscal Multipliers in Brazil: A Sensitivity Analysis on the Structural Identification Procedure. Modern Economy, 10, 2175-2200. https://doi.org/10.4236/me.2019.1010137

Received: September 9, 2019

Accepted: October 28, 2019

Published: October 31, 2019

Copyright $\odot 2019$ by author(s) and Scientific Research Publishing Inc. This work is licensed under the Creative Commons Attribution International License (CC BY 4.0).

http://creativecommons.org/licenses/by/4.0/

\section{cc) (i) Open Access}

\begin{abstract}
The present study measured the effectiveness of Brazilian fiscal policy (the effects of fiscal shocks on output) through several specifications of SVAR models. The focus was on the impact of tax shocks on output, but spending shocks effects were also estimated. Two databases for fiscal variables were used: the official data from National Treasury and a set of alternative data by Gobetti and Orair [1]. The tax multiplier depends on the assumption about the sensitivity of government's revenue to output: the greater the sensitivity, the greater is the tax multiplier. The preferred estimates of tax multipliers in this paper are higher than other estimates in the Brazilian literature. In most identifications both spending and tax (impact) multipliers are below unit.
\end{abstract}

\section{Keywords}

Fiscal Policy, SVAR, Fiscal Multipliers, Brazil

\section{Introduction}

According to the empirical literature on fiscal policy, fiscal multipliers tend to vary between countries and even within the same country over time. The magnitudes of the multipliers are influenced by various macroeconomic conditions and even the strategy of empirical estimation. Among the idiosyncrasies that can affect the extent of fiscal impacts there are the following: the economy openness to external markets, its exchange regime and stage of economic development [2]; the level of public debt [3]; the conduction of monetary policy; ${ }^{1}$ the phase of the ${ }^{1}$ There is some evidence that accommodating monetary policy in developed countries (in macroeconomic environments resembling liquidity trap and of lower-bound interest rates), particularly after the international financial crisis, can increase the effectiveness of fiscal policy. See Blanchard and Leigh [5]. 
economic cycle [4] and the past trajectory of public spending itself [6]. ${ }^{2}$ Most of the empirical literature uses time series methodology to measure the impact of fiscal policy.

In Brazil, fiscal policy empirical literature related to vector autoregressive models (VAR) suggests the existence of "Keynesian" fiscal multipliers, ${ }^{3}$ especially in relation to the macroeconomic effects of government spending. Notwithstanding, there are some literature suggesting the possibility of unconventional effects: fiscal multipliers close to zero and even cases in which output responds negatively (positively) to positive spending (tax) shocks. ${ }^{4}$ Most of the empirical studies on fiscal policy in Brazil also use autoregressive models with structural identification approach (SVAR), even though there are more sophisticated studies (e.g., Bayesian, Markovian regime change, etc.). The present study uses the SVAR most common identification procedure, applying it to two different samples of fiscal data.

In respect to tax shocks, Brazilian literature finds that these tend to be less effective than spending shocks. Reviewing the relevant literature, one will find it is more common to find insignificant responses to tax shocks than to spending shocks, even though, as mentioned, that doesn't mean that spending shocks are always significant. One can find low fiscal effects in both instruments in Mendonça et al. [9] (sign-restriction approach), Cavalcanti and Silva [8], Pires [10] and Oreng [11] (SVAR). ${ }^{5}$ Peres and Ellery Jr. [12] rely on the structural identification procedure of Blanchard and Perotti [5] (henceforth, BP [13]) and find traditional Keynesian effects with statistical significance. More recent works do estimate the value of the multiplier. Focusing on tax multipliers, Pires [14] uses a Markov-switching model and finds an impact tax multiplier between $-\$ 0.2$ and -\$0.3. Matheson and Pereira [15] estimate the accumulated tax multiplier in a Cholesky decomposition, with estimating ranging from $-\$ 0.5$ (one year) and -\$2 (two years). Castelo-Branco et al. [16] uses a MS-SBVAR, obtaining impact multipliers around $-\$ 0.12$ and $-\$ 0.14$. These values are the monetary response of GDP for each $\$ 1$ increase in tax revenues. As mentioned, these values are usually inferior to the spending multipliers. Putting the numbers in perspective, the public spending multiplier calculated by Castelo-Branco et al. can reach $\$ 1.7$ (for government's investment spending).

This study tests the effects of tax shocks on output, vis-à-vis the effects of spending shocks in the Brazilian economy-given the apparent evidence of a lower effectiveness of the tax shocks mentioned in the previous paragraph-from a structural autoregressive model. The question to be answered in this study is the following: given the data generation process (DGP) established by the VAR ${ }^{2}$ Cavalcanti [7] offers a brief review of the literature pointing out the main methodological approaches used to calculate fiscal multipliers (using macroeconomic time series), as well as the main (characteristic) determinants for multiplier values.

${ }^{3}$ That is, positive spending shocks generate positive responses of output levels; and positive tax shocks generate negative responses of output.

${ }^{4}$ See Cavalcanti and Silva [8] and Mendonça et al. [9].

${ }^{5}$ In most cases by simple Cholesky ordering. 
model, under which conditions can a tax shock generate a stronger (or weaker) response of GDP? Or, in other words, under which conditions one can generate a high tax multiplier? This question is answered through a sensitivity analysis on one key-parameter of the structural identification procedure: the income-elasticity of tax revenues. The process of identifying the structural model follows BP [13], assuming various hypothesis for the aforementioned key-parameter. As will be seen in the following, the value one assumes for the income elasticity of tax revenues largely determines the impulse-response function of the tax shocks and, therefore, the tax multipliers.

The procedure of empirically estimating SVAR models implies, at first, estimating the models in a reduced form, which establishes the data generation process for the model's endogenous variables in terms of the past values of its own variables. The model in its reduced form is compatible with various forms of identification. In turn, each identification can be used to access different dynamic responses of the system to shocks. As will be seen in the methodological section, a reduced-form autoregressive model is not appropriate for economic analysis due to correlations between the equations' errors (one cannot conduct a true ceteris paribus analysis). The structural approach imposes a set of contemporaneous correlations between the endogenous variables that becomes an integral part of the empirical model and, if successful, makes all contemporaneous correlations explicit, transforming the errors into white-noise processes.

In terms of choosing contemporary relationships, the Cholesky decomposition-used in various empirical works cited above-imposes a specific ordering on these contemporaneous relationships between endogenous variables, preferably in accordance with economic rationality. In most cases, the SVAR approach can be summarized as a "zeroing" procedure, that is, assuming that some contemporaneous correlations are equal to zero to the point that the system can be exactly identified. BP [13] inaugurated an additional strategy, imposing a specific value for one of the correlations of their three-endogenous variables model (government spending and revenues and output). This key contemporaneous correlation parameter was the income-elasticity of tax revenue. ${ }^{6}$ Adding other reasonable assumptions about the delay or rigidity government spending, identification of the three-variable model was possible. BP's seminal methodology has been adapted to the Brazilian economy by Peres and Ellery Jr. [12] and Mendonça et al. [17]. The former estimated the income-elasticity of tax revenues for the period 1994-2005, finding values very close to the BP's own estimates for the United States; the latter imposed a limited number of values, drawn from empirical SVAR studies from other countries, ${ }^{7}$ but focusing on spending multipliers.

The sensitivity analysis on the income-elasticity of tax revenues reveals, in this ${ }^{6}$ The output-elasticity of government's revenues or, yet, the elasticity of government revenues to output.

${ }^{7}$ Beside the values from BP [13] for the United States, Mendonça et al. [17] uses parameter values from empirical studies from Spain, Slovenia and the European Union, and also compares the SVAR approach with other identification strategies (signal restrictions and threshold-VAR). 
study, that there is a positive relationship between this parameter and the tax-elasticity o output ${ }^{8}$ (the instantaneous response of output to variation in government tax revenues): when its assumed a high sensitivity of tax revenues to output, the result matrix of contemporaneous relationships will be such that taxes will have a great and immediate impact on GDP. These relationships will be passed on to the estimated impulse-response functions and, finally, to multipliers. The estimates of the study suggest that tax shocks cause output responses that are statistically significant when income-elasticity in relatively high, that is, equal or above $2 \% .{ }^{9}$ When the elasticity is exactly equal to $2 \%$ the impact tax multiplier can reach $-\$ 0.53$; when the elasticity is supposed to be between 2.5 and 3 the estimated multiplier rises (in magnitude) to $-\$ 0.81$ and $-\$ 1.1$, respectively. At the same time, the impact multipliers of government spending were estimated between $\$ 0.61$ and $\$ 0.71$, depending on the fiscal data used. The accumulated response to fiscal policy can be even stronger: when the income-elasticity to tax is 2.5 , the accumulated tax multiplier after ten quarters can reach the maximum of $-\$ 1.83$, while the accumulated spending multiplier, for the same horizon, $\$ 1.33$.

The description of the multipliers in intervals in the last paragraph is due to the fact that this study uses two distinct fiscal databases. The first database is the official series of the central government, from the National Treasury. The second database is an alternative, non-official, government series produced by the federal government's economic research institute (Ipea). Ipea's alternative series are described by Gobetti and Orair [1]. This latter database was the result of adjustments on the official data, correcting several issues, from government's revenues and spending classification errors to more serious extra-budgetary problems which alter government's primary results-such the so-called fiscal manipulations (i.e., "pedaladas fiscais"). The authors of this study also produced some adjustments in the official Treasury data (making them more in line with Ipea's series), correcting for the most obvious problems. The methodology of Gobetti and Orair [1], however, is the most complete set of adjustments known to date.

The rest of this article is organized as follow: the next section describes the identification methodology-from the reduced-form VAR model to the structural model. Section 3 describes the two sets of fiscal data available: the fiscal variables from the National Treasury and the alternative database produced by Gobetti and Orair [1]. Section 4 presents the findings, the impulse-response functions from the fiscal shocks and the fiscal multipliers from spending and (several types of) tax shocks. The last section concludes.

\section{Methodology}

This section presents the structural identification methodology for the VAR ${ }^{8}$ The government revenues-elasticity of output or, yet, the elasticity of output to government revenues.

${ }^{9} \mathrm{An}$ income-elasticity of government revenues of $2 \%$ (or, simply, 2) means that for a $1 \%$ increase in real output real revenues rise by $2 \%$. 
models. The following exposition assumes the auto-regressive description of a stationary data generating process. Stationarity and stability result in parameters whose estimations have desirable properties, such as well-behaved impulse-response functions, with variances that are not explosive over the long term. Complete details of the following exposition can be found in most time series econometrics books. ${ }^{10}$

From a theoretical point of view, the structural model is the point of departure in the description of a data generating process. Assume a stationary vector $\boldsymbol{x}_{t}(k \times 1)$ in which each component in $\boldsymbol{x}_{t}$ is a macroeconomic time series, and that the DGP of these components can be represented by an autoregressive model. To maintain the exposition closest as possible to the actual estimations that follows, assume that vector $\boldsymbol{x}_{t}$ has three components: $\boldsymbol{x}_{t}=\left(g_{t}, y_{t}, \tau_{t}\right)^{\prime}$, with $g_{t}, y_{t}$ and $\tau_{t}$ being time series related with, respectively, government spending, the level of activity (output), and government revenues. The equation below describes $\boldsymbol{x}_{t}$ 's dynamic by a $\operatorname{VAR}(p)$ model, in which $p$ is the order of the model, i.e., the number of past components of $\boldsymbol{x}_{t}$ :

$$
\begin{aligned}
& C x_{t}=\Phi_{0}+\Phi(L) x_{t}+B \varepsilon_{t} \\
& \Phi(L)=\sum_{i=1}^{p} \Phi_{i} L^{i}
\end{aligned}
$$

in which $c_{i j}(i, j=1,2,3)$ are the components of the matrix of contemporary correlations $\boldsymbol{C}$ (when $i=j$, then $c_{i i}=1$ ) - that is, each component in $\boldsymbol{x}_{t}$ can be affected contemporarily by the other variables contained in vector $\boldsymbol{x}_{t}$ itself; $\Phi_{0}$ is the vector column whose components are the constant coefficients of each equation and $\Phi_{1}$ is the $(3 \times 3)$ matrix whose components are the past impact coefficients of the macroeconomic variables of vector $\boldsymbol{x}_{t}$, and $\boldsymbol{\varepsilon}_{t}=\left(\varepsilon_{t}^{g}, \varepsilon_{t}^{y}, \varepsilon_{t}^{\tau}\right)^{\prime}$ contains the error terms for each equation. If the autoregressive term in (1) reflects the real DGP, then the components in $\varepsilon_{t}$ are not correlated, and can be written as $\boldsymbol{E}\left(\boldsymbol{\varepsilon}_{t} \boldsymbol{\varepsilon}_{t}^{\prime}\right)=\boldsymbol{I}$, in which the standard errors are inserted in the main diagonal of matrix $\boldsymbol{B}$.

The system of Equation (1) possesses feedbacks: $g_{t}, y_{t}$ and $\tau_{t}$ mutually affect each other in terms of past values. But they also can produce contemporary effects through the terms $c_{i j}$. The error terms in $\varepsilon_{t}$, despite white noise, can have contemporary indirect effects on $g_{t}, y_{t}$ and $\tau_{t}: \varepsilon_{t}^{\tau}$, for example, can produce contemporary indirect effects on $y_{t}$ and $g_{t}$ through $c_{23}$ and $c_{13}$-if these two terms are not equal to zero. The system becomes even more sophisticated more than one type of structural error is allowed to have direct effect on each equation, that is, if the elements outside de main diagonal of $\boldsymbol{B}$ are not equal to zero.

Unfortunately, we cannot estimate the DGP above (the coefficients $c_{i j}, \phi_{0, i}$ and $\phi_{1, i j}$ ) for least squares. The variables $g_{t}, y_{t}$ and $\tau_{t}$ produce contemporary impacts among themselves and the OLS estimates of the system suffer from ${ }^{10}$ See, for example, Enders (2015, Ch. 5) [18], Lütkepohl and Krätzig (2004, Ch. 3-4) [19] and Lütkepohl (2006, Ch. 2-4, 9) [20]. 
a simultaneity bias: the estimated errors will be correlated between equations. Fortunately, it is possible to transform the system into a manageable form. Multiplying both sides by $\boldsymbol{C}^{-1}$ :

$$
\boldsymbol{x}_{t}=\boldsymbol{A}_{0}+\boldsymbol{A}(\boldsymbol{L}) \boldsymbol{x}_{t}+\boldsymbol{u}_{t}
$$

In which,

$$
\begin{gathered}
\boldsymbol{A}_{0}=\boldsymbol{C}^{-1} \boldsymbol{\Phi}_{0} \\
\boldsymbol{A}(\boldsymbol{L})=\boldsymbol{C}^{-1} \boldsymbol{\Phi}(\boldsymbol{L}) \mathrm{e} \\
\boldsymbol{u}_{t}=\boldsymbol{C}^{-1} \boldsymbol{B} \boldsymbol{\varepsilon}_{t} \rightarrow \boldsymbol{C} \boldsymbol{u}_{t}=\boldsymbol{B} \boldsymbol{\varepsilon}_{t} .
\end{gathered}
$$

The components of $\boldsymbol{u}_{t}$ are correlated amongst themselves, but they maintain the property of stationarity with an average equal to zero and variances and covariances which are independent of time, that is, $\boldsymbol{E}\left(\boldsymbol{u}_{t} \boldsymbol{u}_{t}^{\prime}\right)=\mathbf{0}, \boldsymbol{E}\left(\boldsymbol{u}_{t} \boldsymbol{u}_{t}^{\prime}\right)=\boldsymbol{\Sigma}_{u}$ and $\boldsymbol{E}\left(\boldsymbol{u}_{t} \boldsymbol{u}_{s}^{\prime}\right)=\mathbf{0} \quad \forall t \neq s$. In general, it is assumed that $\boldsymbol{B}$ is a diagonal matrix which captures the contemporary effects of structural shocks $\varepsilon_{t}$ on shocks in a reduced form, $\boldsymbol{u}_{t}$.

Equation (2) can be estimated by least squares in a consistent form. It was stated in the introduction that autoregressive models in a reduced form cannot be used for economic analysis. The reason is given above: the error terms are not independent shocks of the variables per se; but rather, are a composition of the true structural shocks $\boldsymbol{\varepsilon}_{t}$. Matrices $\boldsymbol{A}_{0}$ and $\boldsymbol{A}(\boldsymbol{L})$ contain terms that are compositions of the interaction between contemporary relationships $(\boldsymbol{C})$ and the true structural parameters $\left(\Phi_{0}, \Phi(L)\right)$. If it is possible to obtain information about the contemporary relationships, imposing a feasible matrix on (2), then it will be able to recover the original model and measure the real impacts of the structural shocks on the system. The estimation by OLS generates parameter estimates (and errors) in accordance with Equation (3) below:

$$
\boldsymbol{x}_{t}=\hat{\boldsymbol{A}}_{0}+\hat{\boldsymbol{A}}(\boldsymbol{L}) \boldsymbol{x}_{t}+\hat{\boldsymbol{u}}_{t}
$$

In which, $\boldsymbol{E}\left(\hat{\boldsymbol{u}}_{t} \hat{\boldsymbol{u}}_{t}^{\prime}\right)=\hat{\boldsymbol{\Sigma}}_{u}$, and $\hat{\boldsymbol{\Sigma}}_{u}$ is symmetric.

Consider now the imposition of a contemporary correlation matrix $\boldsymbol{A}$ on the reduced form model, pre-multiplying both sides of (3) by it. If $\boldsymbol{A}=\boldsymbol{C}$, the recovered coefficients $\hat{\Phi}_{0}, \hat{\Phi}(\boldsymbol{L})$ are estimated in a manner consistent with the structural parameters in (1), the same could be said about the structural errors, $\hat{\varepsilon}_{t}$. Thus, the problem of identification can be summarized by the choice of matrix $\boldsymbol{A}$-to the extent that it reflects the real set of contemporary correlations between the endogenous variables of the VAR model.

One possible strategy is to assume that the variables of $\boldsymbol{x}_{t}$ are ordered recursively in terms of contemporary impacts (the Cholesky decomposition). It is assumed that there is a hierarchy between the variables-from the "most exogenous" to the "least exogenous". In the case where $\boldsymbol{x}_{t}=\left(g_{t}, y_{t}, \tau_{t}\right)^{\prime}$ the most used recursive arrangement in the literature places the variable associated with government spending $\left(g_{t}\right)$ as the most exogenous (it affects contemporarily the other variables, but is not affected contemporarily by any other variable). Next 
comes the level of activity $\left(y_{t}\right)$, contemporarily affected only by the spending variable). Finally comes the variable associated with taxes $\left(\tau_{t}\right)$, which suffers contemporaneous impacts of the two previous variables. This recursive order stipulates a relationship between $\hat{\boldsymbol{u}}_{t}$ and $\hat{\boldsymbol{\varepsilon}}_{t}$ according to Equation (4):

$$
\begin{aligned}
& \boldsymbol{A} \hat{\boldsymbol{u}}_{t}=\tilde{\boldsymbol{B}} \hat{\boldsymbol{\varepsilon}}_{t} \\
& {\left[\begin{array}{ccc}
1 & 0 & 0 \\
a_{21} & 1 & 0 \\
a_{31} & a_{32} & 1
\end{array}\right]\left[\begin{array}{c}
\hat{u}_{t}^{g} \\
\hat{u}_{t}^{y} \\
\hat{u}_{t}^{\tau}
\end{array}\right]=\left[\begin{array}{ccc}
b_{11} & 0 & 0 \\
0 & b_{22} & 0 \\
0 & 0 & b_{33}
\end{array}\right]\left[\begin{array}{l}
\hat{\varepsilon}_{t}^{g} \\
\hat{\varepsilon}_{t}^{y} \\
\hat{\varepsilon}_{t}^{\tau}
\end{array}\right]}
\end{aligned}
$$

In the Brazilian literature the ordering in (4) had been used by Cavalcanti and Silva [8] and Pires [10], for example. Matrix $\tilde{\boldsymbol{B}}$ is a version of $\operatorname{diag}(\boldsymbol{B})$ of the original $\boldsymbol{B}$ matrix in (1) and ends up being a function of the specific matrix $\boldsymbol{A}$ that will be chosen to identify the structural model. From (4) $\hat{\boldsymbol{u}}_{t}=\left(\boldsymbol{A}^{-1}\right) \tilde{\boldsymbol{B}} \hat{\boldsymbol{\varepsilon}}_{t}$ and the variance-covariance matrix is:

$$
\hat{\boldsymbol{\Sigma}}_{u}=\boldsymbol{E}\left(\hat{\boldsymbol{u}}_{t} \hat{\boldsymbol{u}}_{t}^{\prime}\right)=\left(\boldsymbol{A}^{-1}\right) \tilde{\boldsymbol{B}} \tilde{\boldsymbol{B}}^{\prime}\left(\boldsymbol{A}^{-1}\right)^{\prime}
$$

The symmetrical matrix $\hat{\boldsymbol{\Sigma}}_{u}$-calculated according to (5) and using estimates from (3)-possesses $6\left[=\left(k^{2}+k\right) / 2\right]$ distinct components, which can be utilized to identify 6 system unknowns in (4), again, $k$ being the number of endogenous variables. The Cholesky ordering, together with the restriction given by $\tilde{\boldsymbol{B}}$, guarantees a structural model which can be exactly identified.

In (4) the contemporary impact of output on taxes, $a_{32}$, is determined internally during the identification process. At the same time, the recursive nature of the model restricts the immediate impact of output on government revenues to zero $\left(a_{23}=0\right)$. The impact of the level of activity on taxes and spending are also zero $\left(a_{12}=a_{13}=0\right)$. These last two restriction are actually quite reasonable, when on uses high frequency data: as argued by BP [13], there are institutional ties that do not permit ready government answer to sudden changes on the macroeconomic environment; especially in constitutional regimes there are various phases of negotiations required to alter budget mandates through the legislative branch, and even assuming disproportionally strong executives with broad discretion, the still remains the problem of obtaining reliable information at a timely basis on which the government could act at the same quarter. On the other hand, there is no good argument that can be used to assume that government revenues are not affect contemporaneously by changes on activity levels. This assumption is carried out only to allow exact identification; leaving $a_{23}$ would require restriction elsewhere in $\boldsymbol{A}$, causing just a modification on the recursive ordering, probably with less economic reasoning behind it.

BP [13] proposed a two-fold solution. First, based on the US' database of government revenues, divided by tax type and tax-base, they calculated the short-term (quarterly) sensitivity of government revenues in relation to output (output-elasticity of taxes) for the period of their sample, 1947-1997. The estimated value for this parameter was 2.08. This external information enabled BP to choose a more elaborate identification restriction of matrix $\boldsymbol{A}$ : the external in- 
formation about $a_{32}$ made it possible to let another parameter free, whose information was lacking. Accepting the reasoning of $a_{12}=a_{13}=0$, is became obvious that the free parameter must be $a_{23}$, resulting in the following structural model:

$$
\begin{aligned}
& \boldsymbol{A} \hat{\boldsymbol{u}}_{t}=\tilde{\boldsymbol{B}} \hat{\boldsymbol{\varepsilon}}_{t} \\
& {\left[\begin{array}{ccc}
1 & 0 & 0 \\
a_{21} & 1 & a_{23} \\
a_{31} & a_{32}^{*} & 1
\end{array}\right]\left[\begin{array}{c}
\hat{u}_{t}^{g} \\
\hat{u}_{t}^{y} \\
\hat{u}_{t}^{\tau}
\end{array}\right]=\left[\begin{array}{ccc}
b_{11} & 0 & 0 \\
0 & b_{22} & 0 \\
0 & 0 & b_{33}
\end{array}\right]\left[\begin{array}{c}
\hat{\varepsilon}_{t}^{g} \\
\hat{\varepsilon}_{t}^{y} \\
\hat{\varepsilon}_{t}^{\tau}
\end{array}\right]}
\end{aligned}
$$

Thus, $a_{32}^{*}$ represents a numerical restriction but, at the same time, not equal to zero as the restriction imposed on government spending.

In Brazil, applications of SVAR models are restricted to national quarterly data that begins with 1995. BP [13] approach is adapted first of all by Peres [21]. Peres estimated the income-elasticity of the Brazilian central government revenues to the period from 1994 to 2005, arriving at the value of $2.03 .{ }^{11}$ Peres then uses $a_{32}^{*}=2.03$ to identify his structural model. Note that this value implies a high sensitivity of government revenue to economic activity, and very close to BP's. On the other extreme, Ilzetzki [22] performs exercises of structural identification analogous to (6) for several countries, differentiating between then by the value assumed to the income-elasticity of taxes. For Brazil, the parameter restriction much smaller than Peres', at $a_{32}^{*}=0.76$. Yet, there is the study of Mendonça et al. [17], which tries different values for $a_{32}^{*}$, taking from estimations from different studies from different countries: 0.62 (Spain), 0.87 (Slovenia), 1.54 (EU) and 2.08 (USA). Naturally, different values for $a_{32}^{*}$ implies different structural impulse-responses and fiscal multipliers. Mendonça et al. [17], however, analyzed only government spending multipliers; the focus of the present study is more on the conditions of significant tax multipliers.

In sum, the structural identification approach opens space for various possibilities, depending on key assumption in the identification process. As should be clear by now, at least in small scale fiscal policy autoregressive models, the income-elasticity of taxes is the key parameter for identification. In large scale models, say, when $\boldsymbol{x}_{t}=\left(g_{t}, y_{t}, \tau_{t}, \pi_{t}, i_{t}\right)^{\prime}, \pi_{t}$ and $i_{t}$ being the inflation and interest rates, one also has to search for external information about other set of elasticities. ${ }^{12}$ For this study, the analysis focus on the consequences of disturbing parameter $a_{32}^{*}$, and the access the impacts of the sensitivity analysis on tax multipliers. As will be stablished on Section 4, the choice of the output-elasticity of tax revenues will have a direct impact on the identification of the free parameter $a_{23}$, which measures the instantaneous impacts of government revenues on output and, thus, with consequences for the value of the tax multiplier.

\footnotetext{
${ }^{11}$ One should note that income-elasticity of government revenues being equal to 2.03 simples affirming that the contemporary effect of elevating output on revenues is positive. In the matrix form of (6), this means that the term $a_{32}$ is negative. Greater attention should be given to the interpretation of the estimated parameters in the results section.

${ }^{12}$ See Perotti [23] for an analysis of the SVAR model with the five mentioned variables, and the strategies for restricting the key parameters. Medonça et al. [17], in addition to the small model with three variables, also estimate a model with five variables with an analogous identification procedure.
} 


\section{Data Analysis}

\subsection{Introduction to the Data}

The methodological description established the SVAR methodology assuming the use stationary time series. This section describes the data that will be used as proxies for the (theoretical) variables of government spending and revenues, and also output, as well as their statistical characteristics.

Samples of the high frequency macroeconomic series available in Brazil are quite reduced compared to their counterparts in the main developed nations (the main focus of international literature). However, Brazilian samples do make reasonable estimates possible. The Brazilian Institute of Geography and Statistics (IBGE) produces the National Quarterly Accounts (CNT) series, available beginning in 1995. The CNT generates data such as nominal GDP, the real growth rate ("variation in volume") of GDP proper and GDP categories (consumption, investment, etc.). The volume series (with seasonal adjustment) are available starting in 1996. At most, the CNT database has series with up to 92 observations, from the first quarter of 1995 through the last quarter of 2017. By comparison, US quarterly macroeconomic data dates back at least to the 1950s.

Brazilian fiscal data are less straightforward. There are no official statistics of revenues and expenditures for the Brazilian consolidated government. ${ }^{13}$ In studies analogous to this one, Brazilian researchers face a tradeoff between working with unofficial fiscal estimates-which in general are constructed for specific periods-or work with official data that encompasses the central government, ${ }^{14}$ the latter made available and update on a monthly basis. The National Treasury Secretariat (STN) publishes central government's “above the line” results (primary results) beginning in January 1997. Consolidation of Treasury's series makes it possible to form a quarterly sample consisting of 84 observation from 1997 to 2017. The strategy of using central government's fiscal variables as proxies for consolidated figures has already been used in other empirical works and will also be followed in this study. ${ }^{15,16}$

\footnotetext{
${ }^{13}$ Consolidated government: encompasses the three spheres of government in Brazil: federal, state and municipal (local) governments.

${ }^{14}$ Central government: federal government (National Treasury), Social Security and the Central Bank.

${ }^{15}$ See Peres [21], Peres and Ellery Jr. [12], Ilzetzki [22] and Matheson and Pereira [15] for examples of applications using central government's figures.

${ }^{16}$ Another less attractive possibility is to use Brazilian National Account's public sector series- "net government income" and "government consumption"-available from IBGE's quarterly national accounts. However, this alternative results in further miss specification since a substantial part of government spending is computed as transfers to the private sector and included as private income and consumption (and not on government accounts). This is the case of social benefits (pensions, retirement benefits, low-income social benefits, etc.), which sums' to almost half of the central government's expenditures. Concomitantly, public investment is computed together with private investment in one spending category called "gross formation of fixed capital" (FBCF). These IBGE series had been used in other empirical works, together with unofficial estimates of government's revenues and expenditures. Santos et al. [24] estimated the net tax burden of the Brazilian consolidated government for the period between 1996 and 2009; Santos et al. [25] estimated public sector's spending in gross fixed capital formation that can be combined with IBGE's consumption series. Mendonça et al. [9], Pires [14] and Grudtner and Aragon [26] are examples of applications mixing official and unofficial fiscal series.
} 
Gobetti and Orair [1] show that the National Treasury's fiscal series has problems, by construction, that can be group into three types: first, there is the composition problem - which are errors in the allocation of some sources of revenue and expenditure, within subcategories, which do not affect the levels of net revenues or primary spending ${ }^{17}$-distorting the relative proportions of some revenues and expenditures subcategories; second, there is what will be called the amount problem (or, "sum problems")-which originate from the inclusion, at some point in time, of intra-budgetary operations resulting in the increase of primary revenue and expenditures in the same amount, also not distorting primary result but distorting the level of the series and their dynamic analysis (growth rates); finally, there is the accounting maneuver problem, related to extra-budgetary operations which affect the analysis in terms of the rate of growth of the fiscal series as well as the primary result for various years. ${ }^{18}$ Gobetti and Orair [1] constructed new estimates of net revenue and primary spending (and subcategories) correcting these three problems for the period from 1997 up to the second quarter of 2017 (monthly and quarterly frequencies). This study benefits from these figures, estimating the VAR models of fiscal policy using both fiscal sources-Gobetti and Orair's (Ipea) figures and Treasury database (Figure $1)$.

In addition to providing an alternative database, Gobetti and Orair's study [1] is important because it elucidates and clarifies some procedures that can be performed with the National Treasury fiscal series that are available online, making possible to improve the quality of the National Treasury's revenue and spending series, correcting part of the problems mentioned above (especially the composition and amount problems) - simply by addition or subtraction of certain revenue and expenditures subcategories from the totals that make up the official primary revenue and spending of the central government. Most of the accounting maneuvers cannot be resolved with the same ease, and this is one of the reasons why Gobetti and Orair's study [1] is the result of a large research effort within Ipea. Nonetheless, the most serious problem can be easily corrected: the government's capitalization of Petrobrás (Federal government's oil company), occurred in September of 2010.

The capitalization of Petrobrás was an operation that falls into the type described as accounting maneuvers. This operation represented a significant increase in government's net revenue ( $R \$ 74.8$ billion) and primary spending ${ }^{17} \mathrm{Net}$ revenue is defined as total revenues minus transfers to states and municipalities (constitutional or voluntary). This is the quantity of financial resources that the federal government has available to pay for its expenses. In this paper the term "net revenue" will be used together with "primary revenue" interchangeably.

${ }^{18}$ Including into these extra-budgetary procedures there are those that became known in the Brazilian press as fiscal pedaling ("pedaladas fiscais"). One example of this kind of procedure is what happened during some years, and masked central government's primary result, that is, the delaying of transfers of resources $t$ public banks, referring to disbursement made by the banks in the name of the government to pay for subsidies of social programs. When the federal government finally honored these commitments with these financial institutions in 2015 , these expensed entered into the accounting of the Treasury's cash flow. 
(a) Real GDP (in logs)

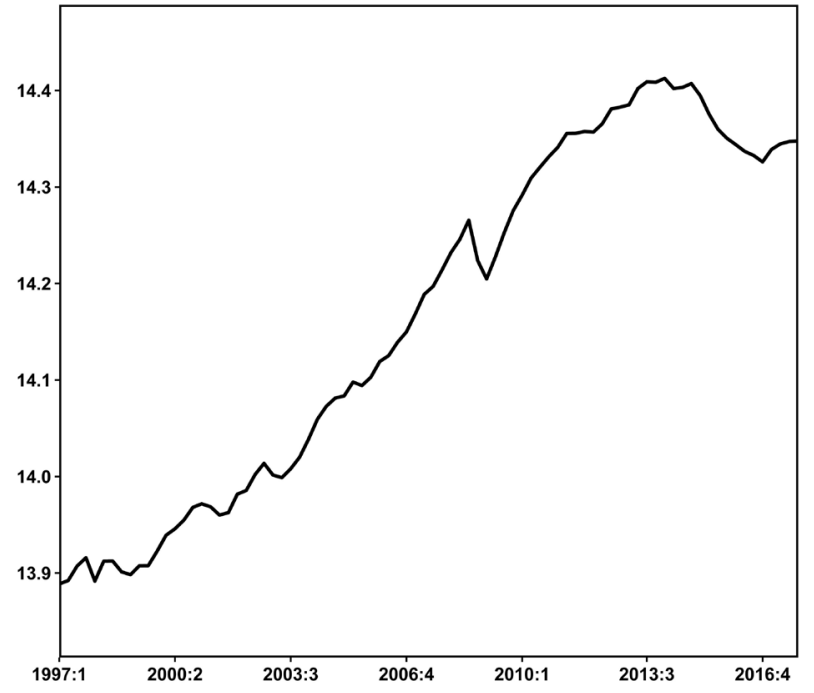

(c) Net revenues (in logs)

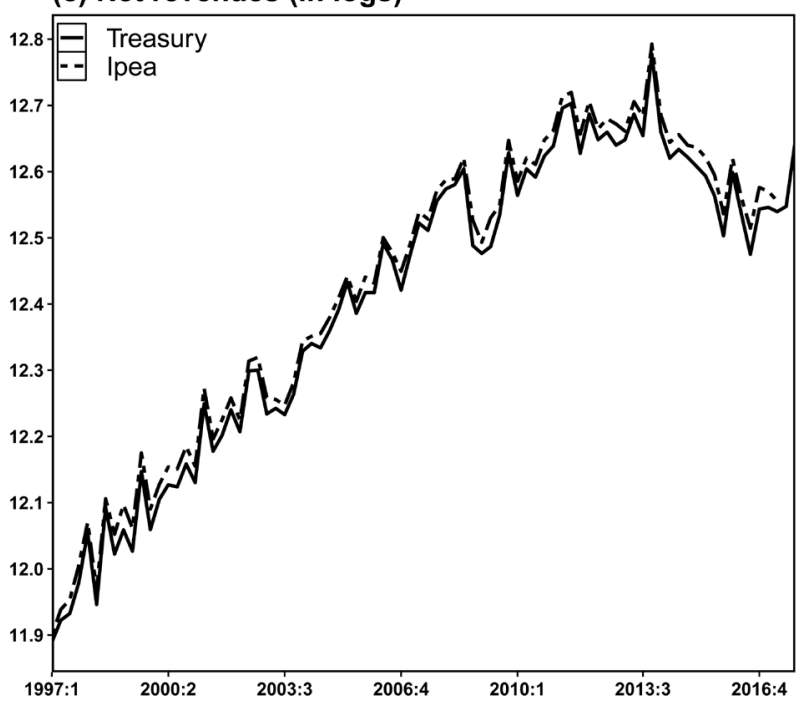

(e) Primary expenses (in logs)

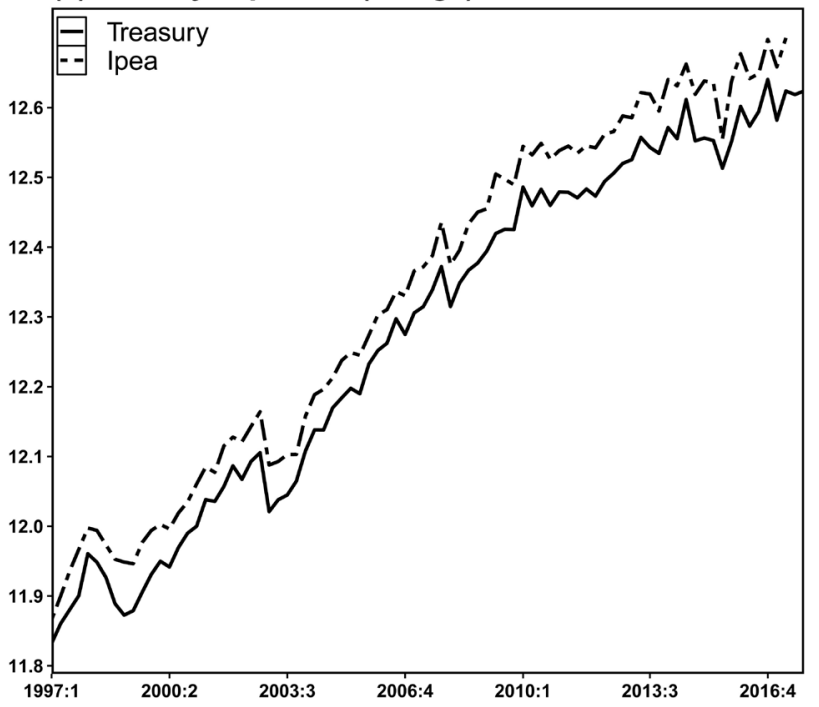

(b) Real GDP (variation rate)

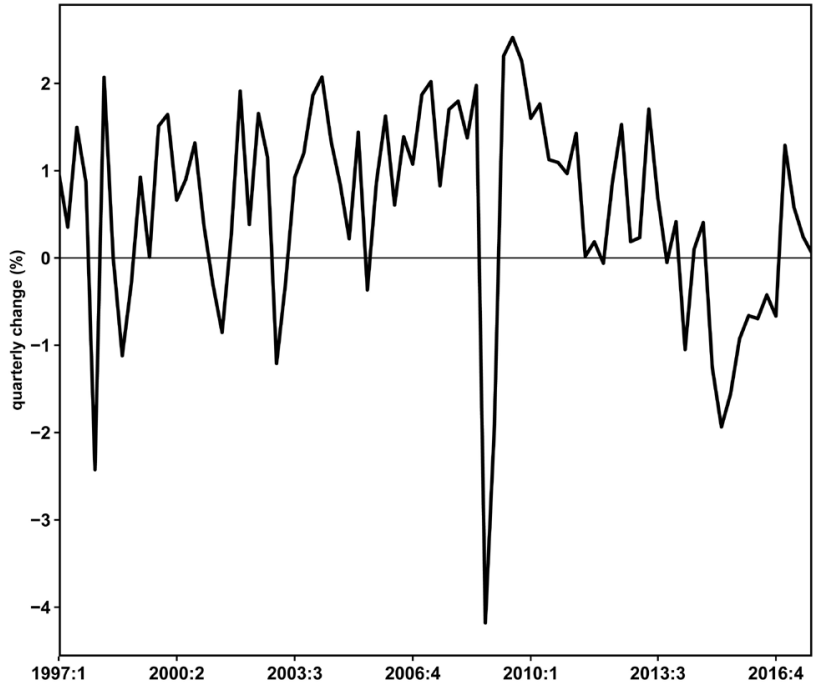

(d) Net revenues (variation rate)

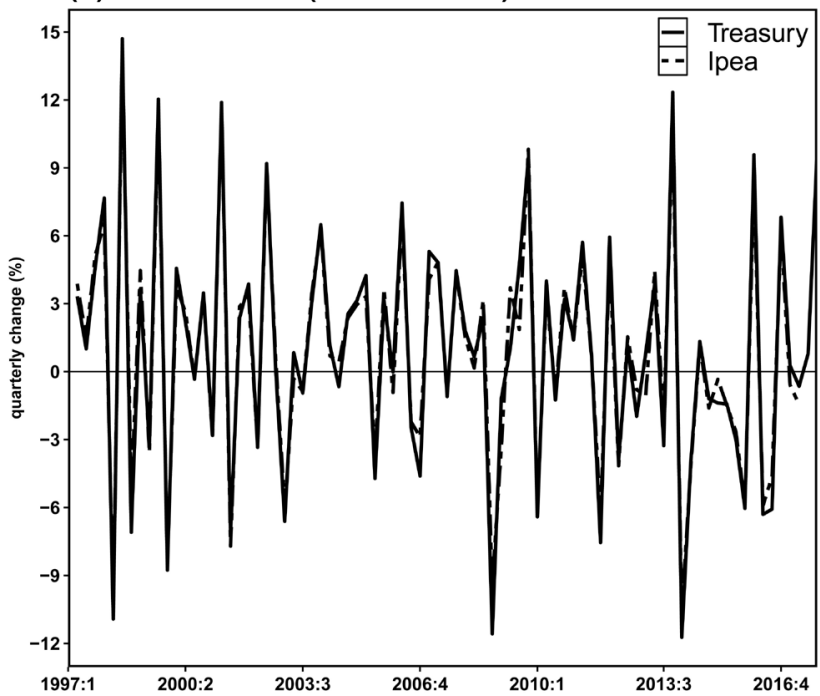

(f) Primary expenses (variation rate)

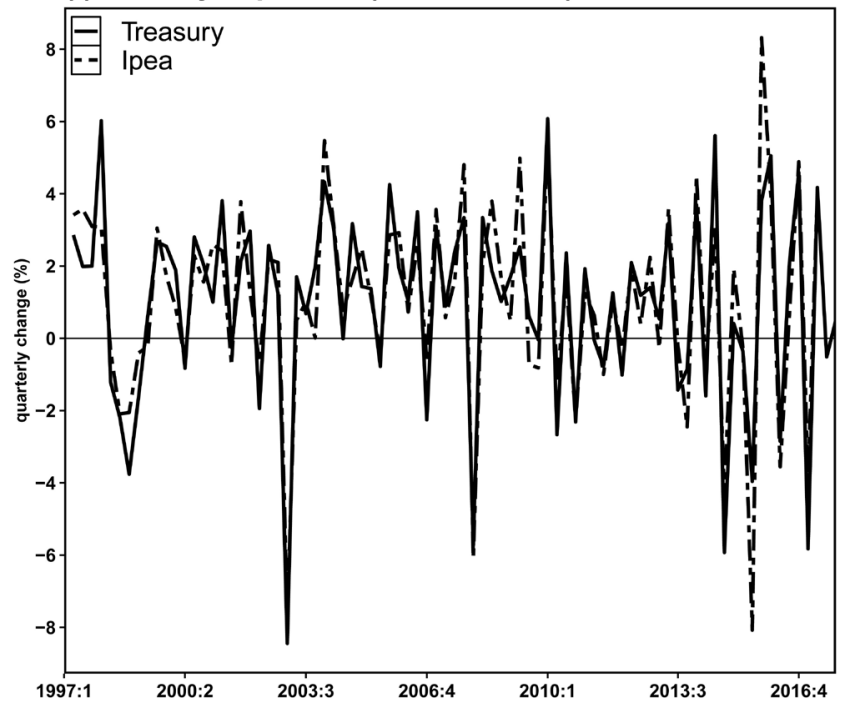

Figure 1. The central government's GDP, revenue and spending data. Source: IBGE, STN and Gobetti and Orair [1]. 
( $R \$ 42.9$ billion). These figures were deduced from the Treasury's database (as well as other adjustments) for form the new Treasury's series actually used in the estimations that follows. For the remaining of this article, one should understand mentions to "Treasury" fiscal series as those series already after adjustments; while the "Ipea" series as those produce by Gobetti and Orair [1] together with IPEA. As mentioned above, both sources will be used to estimate SVAR models and access fiscal policy effectiveness.

As mentioned at the beginning of this section, the nominal GDP is available starting in 1995. Real growth rates are available since 1996. From nominal GDP and growth rates with seasonal adjustments one can construct the real GDP at 2017:4 prices. Growth rates without seasonal adjustments and nominal GDP can be combine to derive the quarterly implicit deflator. ${ }^{19}$ The implicit deflator is then used to construct real fiscal series (from both sources) also at 2017:4 prices. Seasonal variations were removed from the fiscal series using ARIMA-X13 method.

In Figure 1, the left side panels display real GDP and government's net revenue and primary spending series, adjusted seasonally and in logarithmic transformation. The right-side panels exhibit growth rates from the left-side variables.

One more comment should be made about the adjustments made on the fiscal series. The examination of panel (e) reveals the difference in levels between the Treasury and Ipea spending series. This discrepancy is not due only to the incomplete adjustment of the Treasury database, but also because of the different components classifications that form primary spending in both data sources. In fact, panels $(e)$ and $(f)$ do not exhibit the definition of total primary spending: rather, the primary spending series in Figure 1 are already deduced from some spending categories beyond those already mentioned before. These last deductions are important because they refer to that part of primary spending that are highly sensitive to economic cycles, that is, that part of public spending that varies almost automatically (if not totally) when output increases or decreases. In the SVAR literature, these (minor) types of primary spending produce difficulties to adopt the identification strategy in Section 2, that is, they are not compatible with the assumption that government spending cannot respond to economic conditions. If fact, it is difficult to imagine that government officials can decide a systematic spending response to sudden changes in the macroeconomic environment, but this argument in muted if there are some types of expenditures that can vary automatically and contemporaneously with output. Those kinds of expenditures are related to the so called "automatic stabilizers" and, for the identification strategy to work, they should be taken out. In examining the broad categories of primary spending in both Treasury and Ipea series one can identify some types that fit more or less the characteristic of automatic stabilizers: subsidies and unemployment insurance benefits, for the Treasury, and a broad cate${ }^{19}$ That is, the implicit deflator (inflation measure) in relation to the previous quarter. The implicit deflator published by IBGE does not measure quarterly inflation, but rather the variation in prices during the quarter in relation to the average prices of the previous year. 
gory of subsidies for the Ipea database. Deducing these categories from total primary spending series from each source, one arrives at the figures on panels (e) and $(f)$ of Figure $1 .^{20}$

The next subsection is a brief summary of the statistical properties of all the time series used in the autoregressive models estimated in Section 4. A complete analysis in available upon request. ${ }^{21}$ During the diagnosis, it was verified a sudden change in the DGPs of several series, especially the fiscal series, for the period after 2014-when the recent Brazilian fiscal crisis began. From 2015 onward, with the economy in full recession, GDP and net revenues began to contract continually. ${ }^{22}$ Expenditures did not suffer sudden and continuous contractions, but rather began to exhibit greater volatility than observed up until that point. This unstable dynamics at the end of the sample period is responsible for poorer fit of both univariate and multivariate autoregressive models tried, also affecting formal test of unit root. It's possible that the recent recession with fiscal crisis has constituted a permanent shock into Brazilian macroeconomic data-a hypothesis that needs to be explored in future research. What the data shows, up until now, is a more sophisticated dynamic in the last period of the complete sample, apparently distinct from the first interval (that is, until 2014). For this study, the option chosen was to perform the analysis for the period before the recent crisis. Thus, the sample period for the unit-root tests of the next subsection and the VAR models of the next section ranges from the first quarter of 1997 to the third quarter of 2014-before the contagion of the fiscal crisis and recession in the last quarter of that year.

\subsection{Unit Root}

The diagnosis of a data generation process defines the way in which variables should be previously transformed, when necessary, before the actual estimation of the VAR model. A mistaken diagnosis of the stochastic characteristics of the components of vector $\boldsymbol{x}_{t}$ (in (3)) would invalidate all of the subsequent analysis. This subsection offers a summary of the unit root tests applied to the fiscal series and output. In panels $(a),(c)$ and (e) of Figure 1, it is already possible to admit the non-stationary nature of time series-all with a strong growth trend. It is not possible to determine graphically, however, the cause: whether it is because of the presence of the unit root or just a result of deterministic trends. In even smaller samples, we know that both types of processes can generate quite similar series.

Unit root tests measure the degree of persistence of a time series. When they are high enough, from a statistical point of view, the degree of persistence indicates a series with a stochastic tendency-i.e., with a unit root. In this case, im${ }^{20}$ Given the amount of adjustments necessary on the fiscal series, a complementary material to accompany this article is available upon request. The extra material describes in more detail the two fiscal databases, adjustments and expenditures subcategories for each source.

${ }^{21}$ Reference to the complementary material. See previous footnote.

${ }^{22} \mathrm{Net}$ revenues begin to fall before the beginning of the economic recession, and later became stagnant at a very low level. 
pacts of shocks suffered by the series will have permanent effects. Contrary, shocks suffered by stationary time series-whether around a tendency or not, whether an ascending or descending trend-dissipate over time. The larger the persistence of a series, the more time it will need to dissipate the shock. ${ }^{23}$

Let $y_{t}$ be an ordinary time series. ${ }^{24}$ To formally test the degree of persistence in $y_{t}$, the series can be described as an autoregressive process $y_{t}=\rho y_{t-1}+\boldsymbol{z}_{t}^{\prime} \boldsymbol{\beta}+e_{t}$, in which $z_{t}$ is a vector whose components are control variables (e.g., constants, tendencies, dummies, etc.). The coefficient $\rho$ measures the degree of persistence which, if close to 1 from the statistical perspective, allows one to affirm the series as a unit root process. Unit root tests test the null hypothesis $H_{0}: \rho=1$ against the alternative hypothesis $H_{A}: \rho<1$ :

$$
\begin{aligned}
& H_{0}: y_{t}=\rho y_{t-1}+\boldsymbol{z}_{t}^{\prime} \boldsymbol{\beta}+e_{t} \\
& H_{A}: y_{t}=\rho y_{t-1}+\boldsymbol{z}_{t}^{\prime} \boldsymbol{\beta}+e_{t}
\end{aligned}
$$

Table 1 displays the results of these three unit root tests, which are among the most traditional tests used in the literature: the Augmented Dickey-Fuller test (ADF), the Phillips-Perron test (PP) and the Dickey-Fuller Generalized Least Squares test (DF-GLS). ${ }^{25}$ In the DF-GLS test, the series passes through a transformation through a regression of generalized least squares before the ADF regression per se. Under the null hypothesis, the parameters estimated by the tests do not possess conventional distributions. The hypothesis tests are realized using specific critical values. The results suggest that GDP and the fiscal variables are highly persistent series. The $\phi$ statistics of the ADF indicate unit root processes with drift (constant term). In the PP and DF-GLS tests, the null hypothesis is rejected, but only when the alternative includes a tendency.

When structural breaks occur, the power of conventional tests trends towards zero. When they are not explicitly introduced in regressions, the structural breaks produce biases in the coefficient estimates. Table 2 displays the results of Zivot and Andrews' test [27] - a test of an endogenous structural break-applied to the same database as Table 1. The null hypothesis continues to be the presence of a unit root: but it is possible to construct three types of alternative hypotheses: admitting a structural break in the constant; admitting a structural break in the tendency; or both. The alternative hypotheses in the Zivot-Andrews test are different from the functional form in (7), but the fundamental idea remains the same, i.e., rejecting or not $H_{0}: \rho=1$.

The Zivot-Andrews test is an endogenous structural break test because the point of the break is chosen in an optimal manner within the structure of the test itself. This procedure tests the null hypothesis of a unit root against the alternative hypothesis of a structural break, in which the location of the break is tested for all possible periods within a subinterval of the sample (breaks near the extremities are ignored to guarantee a minimum number of observations in each ${ }^{23}$ See Enders (2015, p. 181-89) [18] for a succinct description of the characteristics of a series with a stochastic and determinist tendency.

${ }^{24}$ Not necessarily the output, as in the methodological section.

${ }^{25}$ Also known as ERS test. 
Table 1. Unit root tests (ADF, PP, DF-GLS).

\begin{tabular}{|c|c|c|c|c|c|c|c|c|c|c|c|c|}
\hline & \multirow{2}{*}{$\mathrm{H}_{\mathrm{A}}^{5,6}$} & \multicolumn{5}{|c|}{$\mathrm{ADF}$} & \multicolumn{2}{|r|}{$\mathrm{PP}$} & \multicolumn{4}{|c|}{ DF-GLS } \\
\hline & & $p^{3}$ & $\gamma^{4}$ & $\tau^{7}$ & $\phi^{7}$ & $\rho$ & $\rho$ & $(t$-stat $)$ & $p$ & $\gamma^{4}$ & $(t$-stat $)$ & $\rho$ \\
\hline \multicolumn{13}{|c|}{$-I B G E$} \\
\hline \multirow{2}{*}{ GDP } & tend. & 1 & -0.2127 & $(-2.93)$ & $(4.38)$ & 0.79 & 0.87 & $(-2.57)$ & 1 & -0.2036 & $(-2.43)$ & 0.80 \\
\hline & const. & 1 & -0.006 & $(-0.71)$ & $(6.24)^{\star *}$ & 0.99 & 1.00 & $(0.10)$ & 1 & -0.0147 & $(-0.46)$ & 0.99 \\
\hline \multicolumn{13}{|c|}{ Panel II-National Treasury } \\
\hline \multirow{2}{*}{ Net revenues } & tend. & 1 & -0.33 & $(-2.34)$ & $(3.52)$ & 0.67 & 0.49 & $(-4.56)^{* * *}$ & 1 & -0.22 & $(-1.97)$ & 0.78 \\
\hline & const. & 1 & -0.05 & $(-1.65)$ & $(3.78)$ & 0.95 & 0.95 & $(-1.95)$ & 1 & 0.01 & $(-0.59)$ & 1.01 \\
\hline \multirow{2}{*}{ Primary expenses } & tend. & 1 & -0.22 & $(-2.25)$ & $(2.75)$ & 0.78 & 0.73 & $(-3.33)^{\star}$ & 0 & -0.27 & $(-3.25)^{\star \star}$ & 0.73 \\
\hline & const. & 1 & -0.01 & $(-0.93)$ & $(12.5)^{\star * *}$ & 0.99 & 0.99 & $(-0.42)$ & 0 & 0.02 & $(1.82)$ & 1.02 \\
\hline \multirow{2}{*}{ Discretionary expenses } & tend. & 1 & -0.22 & $(-2.30)$ & $(2.83)$ & 0.78 & 0.80 & $(-2.66)$ & 0 & -0.19 & $(-2.57)$ & 0.81 \\
\hline & const. & 1 & -0.01 & $(-0.30)$ & $(1.80)$ & 0.99 & 0.98 & $(-0.34)$ & 0 & 0.00 & $(0.05)$ & 1.00 \\
\hline \multirow{2}{*}{ Mandatory expenses } & tend. & 1 & -0.05 & $(-0.86)$ & $(2.31)$ & 0.95 & 0.88 & $(-1.76)$ & 4 & -0.05 & $(-0.78)$ & 0.95 \\
\hline & const. & 1 & -0.02 & $(-2.11)$ & $(21.2)^{\star * *}$ & 0.98 & 0.99 & $(-1.17)$ & 3 & 0.01 & $(1.35)$ & 1.01 \\
\hline \multicolumn{13}{|c|}{ Panel III-Ipea } \\
\hline \multirow{2}{*}{ Net revenues } & tend. & 1 & -0.31 & $(-2.14)$ & $(3.06)$ & 0.69 & 0.50 & $(-4.48)^{\star * \star}$ & 1 & -0.18 & $(-1.73)$ & 0.82 \\
\hline & const. & 1 & -0.04 & $(-1.58)$ & $(4.00)^{*}$ & 0.96 & 0.95 & $(-2.09)$ & 1 & 0.01 & $(0.71)$ & 1.01 \\
\hline \multirow{2}{*}{ Primary expenses } & tend. & 1 & -0.21 & $(-2.20)$ & $(2.53)$ & 0.79 & 0.76 & $(-3.13)$ & 3 & -0.30 & $(-3.37)^{\star \star}$ & 0.70 \\
\hline & const. & 1 & -0.01 & $(-0.74)$ & $(10.9)^{* * *}$ & 0.99 & 0.99 & $(-0.69)$ & 3 & 0.02 & $(1.62)$ & 1.02 \\
\hline \multirow{2}{*}{ Costs and Investments } & tend. & 8 & -0.20 & $(-1.77)$ & $(2.27)$ & 0.80 & 0.78 & $(-2.66)$ & 0 & -0.20 & $(-2.21)$ & 0.80 \\
\hline & const. & 8 & 0.02 & $(-0.32)$ & $(1.63)$ & 0.98 & 0.97 & $(-0.47)$ & 1 & 0.03 & $(0.77)$ & 1.03 \\
\hline \multirow{2}{*}{ Other expenses } & tend. & 1 & -0.05 & $(-0.77)$ & $(2.25)$ & 0.95 & 0.88 & $(-1.80)$ & 4 & -0.04 & $(-0.70)$ & 0.96 \\
\hline & const. & 1 & -0.02 & $(-2.08)$ & $(22.5)^{\star * *}$ & 0.98 & 0.99 & $(-1.75)$ & 3 & 0.01 & $(1.31)$ & 1.01 \\
\hline
\end{tabular}

Source: Prepared by the authors. Notes: 1$){ }^{\star} p<0.1 ;{ }^{\star *} p<0.05 ;{ }^{* *} p<0.01$. 2) Tests applied in logarithmic transformations of levelled series. 3) $p$ is the number of lags of the terms $\Delta y$ used in the regressions. 4) In the ADF and DF-GLS tests, the regressions have the format $\Delta y_{t}=\gamma y_{t-1}+\boldsymbol{x}_{t}^{\prime} \boldsymbol{\beta}+e_{t}$, in which $\gamma=\rho-1$. The null hypothesis $H_{0}: \gamma=0$ is equivalent to $\left.H_{0}: \rho=1.5\right) H_{A}: y_{t}=a_{0}+\rho y_{t-1}+\boldsymbol{x}_{t}^{\prime} \boldsymbol{\beta}+e_{t}$, in which $\boldsymbol{x}_{t}$ contains past terms $\Delta y_{t-i}$ (ADF and DF-GLS). 6) $H_{A}: y_{t}=a_{0}+\rho y_{t-1}+\boldsymbol{x}_{t}^{\prime} \boldsymbol{\beta}+e_{t}$, in which $\boldsymbol{x}_{t}$ contains past terms $\Delta y_{t-i}$ (ADF and DF-GLS). 7) If $H_{A}$ has a tendency, the columns $\tau$ and $\phi$ express the statistics $\tau_{\tau}\left(H_{0}: \gamma=0\right)$ and $\phi_{3}\left(H_{0}: \gamma=a_{2}=0\right)$; if $H_{A}$ contains just one constant, the columns $\tau$ and $\phi$ exhibit the statistics $\tau_{\mu}\left(H_{0}: \gamma=0\right)$ and $\phi_{3}\left(H_{0}: \gamma=a_{0}=0\right)$.

Table 2. Zivot and Andrews [26] unit root tests.

\begin{tabular}{|c|c|c|c|c|c|c|c|c|c|c|}
\hline & \multirow{2}{*}{$\mathrm{H}_{\mathrm{A}}$} & \multicolumn{3}{|c|}{$k=0$} & \multicolumn{3}{|c|}{$k=2$} & \multicolumn{3}{|c|}{$k=4$} \\
\hline & & Break & $\rho$ & $(t$-stat $)$ & Break & $\rho$ & (t-stat) & Break & $\rho$ & $(t$-stat $)$ \\
\hline \multicolumn{11}{|c|}{ Panel I-IBGE } \\
\hline \multirow{3}{*}{ GDP } & both & 1997:4 & 0.80 & $(-3.27)$ & $1997: 4$ & 0.79 & $(-3.36)$ & 1998:2 & 0.78 & $(-3.12)$ \\
\hline & tend & 1998:4 & 0.80 & $(-3.09)$ & $2001: 3$ & 0.70 & $(-3.09)$ & $1998: 4$ & 0.79 & $(-2.90)$ \\
\hline & const & $1997: 4$ & 0.80 & $(-3.29)$ & $2006: 4$ & 0.77 & $(-3.68)$ & $2006: 4$ & 0.77 & $(-3.40)$ \\
\hline \multicolumn{11}{|c|}{ Panel II-National Treasury } \\
\hline Net revenues & both & 2008:3 & 0.08 & $(-7.42)^{\star * *}$ & $2008: 3$ & -0.03 & $(-4.85)^{\star}$ & $2008: 3$ & -0.05 & $(-3.53)$ \\
\hline
\end{tabular}




\begin{tabular}{|c|c|c|c|c|c|c|c|c|c|c|}
\hline \multicolumn{11}{|l|}{ Continued } \\
\hline & tend & $2008: 1$ & 0.11 & $(-7.18)^{\star * \star}$ & $2008: 1$ & 0.02 & $(-4.62)^{\star *}$ & 2008:1 & -0.01 & $(-3.45)$ \\
\hline \multirow{4}{*}{ Primary expenses } & const & $2012: 1$ & 0.25 & $(-6.34)^{\star * *}$ & 2012:1 & 0.32 & $(-3.70)$ & $2012: 2$ & 0.45 & $(-2.39)$ \\
\hline & both & $2005: 3$ & 0.60 & $(-4.21)$ & $2005: 3$ & 0.55 & $(-3.98)$ & $2005: 3$ & 0.47 & $(-4.17)$ \\
\hline & tend & 1999:1 & 0.69 & $(-3.68)$ & 1998:4 & 0.67 & $(-3.45)$ & 2010:1 & 0.55 & $(-4.01)$ \\
\hline & const & $2005: 3$ & 0.60 & $(-4.24)$ & $2005: 3$ & 0.55 & $(-4.07)$ & $2005: 3$ & 0.44 & $(-4.49)$ \\
\hline \multicolumn{11}{|c|}{ Panel III-Ipea } \\
\hline \multirow{3}{*}{ Net revenues } & both & $2008: 3$ & 0.13 & $(-7.13)^{* * *}$ & $2008: 3$ & 0.05 & $(-4.60)$ & 2007:1 & 0.11 & $(-3.24)$ \\
\hline & tend & $2008: 1$ & 0.14 & $(-7.00)^{\star * \star *}$ & 2011:2 & 0.19 & $(-4.50)^{\star *}$ & 2008:1 & 0.13 & $(-3.14)$ \\
\hline & const & $2012: 1$ & 0.26 & $(-6.35)^{\star * *}$ & $2012 ; 1$ & 0.32 & $(-3.79)$ & 2012:1 & 0.48 & $(-2.42)$ \\
\hline \multirow{3}{*}{ Primary expenses } & both & $2005: 3$ & 0.62 & $(-4.15)$ & $2005: 3$ & 0.62 & $(-3.42)$ & 2008:2 & 0.52 & $(-4.06)$ \\
\hline & tend & 1999:1 & 0.72 & $(-3.54)$ & 1998:4 & 0.73 & $(-2.97)$ & 2010:1 & 0.61 & $(-3.74)$ \\
\hline & const & $2005: 3$ & 0.63 & $(-4.20)$ & $2005: 3$ & 0.62 & $(-3.60)$ & $2005: 3$ & 0.52 & $(-4.14)$ \\
\hline
\end{tabular}

Source: Prepared by the Authors. Notes: 1$\left.)^{\star} p<0.1 ;{ }^{\star *} p<0.05 ;{ }^{* *} p<0.01 .2\right)$ Tests applied in logarithmic transformations of levelled series.

of the partitions). The point chosen for the break is that which generates a coefficient $\rho$ most unfavorable for the null hypothesis, i.e., which generates a t-statistic as low as possible. On the other hand, the $\rho$ coefficient possesses its own distribution with higher critical points and broader intervals of confidence, which make it difficult to reject the null hypothesis in comparison with traditional tests. Also, the Zivot-Andrews test regressions can contain control regressors of past terms of the first difference between $y_{t}$, and $\Delta y_{t-i}$. It is convenient to choose the optimal number of past terms $k$, through information criteria. The inclusion of the past terms seeks to establish a regression with a better fit and stationary residuals.

In the Table 2 application, the Schwartz information criterion ${ }^{26}$ (SBC) chooses $k=0$ for all of the tested series. The null hypothesis of the unit root is not rejected by the GDP and the two series of primary spending. Net revenues from both sources (Ipea and the Treasury), would be compatible with stationary processes around the tendencies with structural breaks. This result, if true, would demand different transformations between the series included in the estimated VAR models. A detailed analysis of these tests could alter this preliminary conclusion. Table 2 shows the results of the Zivot-Andrews tests for $k=0,2,4$. It is possible to affirm that the rejection of the null hypothesis is not robust: the values of the SBC criterion for $k$ between 0 and 4 are very similar to each other; moreover, they do not maintain the rejection of the null hypothesis in the case of net revenues when the past terms $\Delta y_{t-i}$ are added-especially when the formation of the alternative hypothesis inserts a break just in the constant term (the model with drift is the most indicated model according to the ADF statistics). The authors conclude in favor of the reasonability of the unit root hypothesis for all of the analyzed series.

${ }^{26}$ Schwartz Bayesian Criterion (SBC). 
The standard procedure of transforming series with stochastic tendencies into stationary series is based on the application of the operator on the first difference. Returning to understand $\boldsymbol{x}_{t}=\left(g_{t}, y_{t}, \tau_{t}\right)^{\prime}$ as a vector of endogenous variables from a VAR model of fiscal policy, as already put forth in the methodology, with the components $g_{t}, y_{t}$ and $\tau_{t}$ representing the series associated with the government's primary expenses, GDP and net revenues, these variables should not be inserted on a level, but rather as variation rates (i.e., the first difference of the logarithms). ${ }^{27}$ The use of growth rates offers the additional benefit that the matrix components of contemporary correlations $\boldsymbol{A}$ can now be interpreted as elasticities.

\section{Results}

In addition to the results of this sensitivity analysis of the tax income-elasticity parameter in terms of the components of the matrix of contemporary correlations, this section also exhibits impulse-response functions for fiscal shocks, with an emphasis on output responses-to tax shocks under the various hypotheses. Based on IRFs, fiscal multipliers were also calculated and are displayed in Table 4.

During Section 2, we argued that the income-elasticity parameter for revenues was estimated in previous works to be between 0.76 [22] and 2.03 [21]. In an unpublished work, the authors of the present study have also calculated the (instantaneous) income-elasticity of government revenues following their own approach. The authors' method consists of measuring the cyclical response of fiscal policy variables (revenues and expenses) for a specific event: the GDP shock due to the impact of international financial crisis in the third quarter of 2008. The value income-elasticity of tax revenues was calculated for the same two samples of fiscal data used in this study in a VAR model for the same period (1997:1-2014:3), but adding dummies in the reduced-form model to capture singular events, a la Ramey and Shapiro [28]. The income-elasticites of tax revenues calculated by this latter methodology varied between 2.6 (Treasury) and 2.1 (Ipea). ${ }^{28}$

Table 3 displays the identifications of matrix $\boldsymbol{A}$ according to the various hypotheses in terms of the value of parameter $a_{32}^{*}$ (see Equation (6)), i.e., the estimates of free parameters $a_{i j}$ in accordance with each hypothesis. Table 3 displays the estimations of $\boldsymbol{A}$ which range from a lower value of $\left|a_{32}^{*}\right|=0.25$ (close to 0.5 percentage points below the value used by Ilzetzki [22]) to a maximum value of $\left|a_{32}^{*}\right|=3$ (which surpasses the estimates of Peres [21] by almost 1 percentage point, and is superior to the authors' maximum estimate by 0.4 p.p.). Table 3 exposes the existence of a positive relationship between the parameters $a_{32}$ and $a_{23}$ : the Brazilian fiscal data and the Brazilian macroeconomic data are ${ }^{27}$ For a better exposition of the results, the rates have been multiplied by 100 .

${ }^{28}$ Since the dummy variables represent exogenous events-whether they have to do with fiscal policy or output-in the VAR model with dummies it was not necessary to have an identification strategy for the matrix of contemporary correlations: the dummy coefficient already represents exogenous effects; and the impulse-response functions derived from them correspond to the system's structural responses. 
Table 3. Analysis of the sensitivity of parameter $a_{32}$.

\begin{tabular}{|c|c|c|c|c|c|c|c|}
\hline \multirow{2}{*}{$a_{\mathrm{ij}}$} & \multicolumn{7}{|c|}{$\left|a_{32}\right|$ (income-elasticity of revenues) } \\
\hline & $=0.25$ & $=0.75$ & $=1.25$ & $=1.75$ & $=2$ & $=2.5$ & $=3$ \\
\hline \multicolumn{8}{|c|}{ (A) National Treasury } \\
\hline \multirow[b]{2}{*}{$a_{21}$} & -0.08 & $-0.1^{*}$ & $-0.11^{*}$ & $-0.13^{* *}$ & $-0.14^{* *}$ & $-0.16^{\star *}$ & $-0.19^{* *}$ \\
\hline & $(0.05)$ & $(0.06)$ & $(0.06)$ & $(0.06)$ & $(0.06)$ & $(0.07)$ & $(0.08)$ \\
\hline \multirow[b]{2}{*}{$a_{31}$} & $-0.47^{\star *}$ & $-0.42^{* *}$ & $-0.36^{*}$ & -0.31 & -0.28 & -0.23 & -0.18 \\
\hline & $(0.21)$ & $(0.21)$ & $(0.21)$ & $(0.21)$ & $(0.21)$ & $(0.22)$ & $(0.23)$ \\
\hline$a_{32}$ & -0.25 & -0.75 & -1.25 & -1.75 & -2 & -2.5 & -3 \\
\hline \multirow[b]{2}{*}{$a_{23}$} & $-0.06^{* *}$ & -0.02 & 0.01 & 0.05 & $0.07^{*}$ & $0.11^{* *}$ & $0.16^{* *}$ \\
\hline & $(0.03)$ & $(0.03)$ & $(0.03)$ & $(0.04)$ & $(0.04)$ & $(0.05)$ & $(0.06)$ \\
\hline \multicolumn{8}{|c|}{ (B) Ipea } \\
\hline \multirow[b]{2}{*}{$a_{21}$} & $-0.11^{\star}$ & $-0.13^{* *}$ & $-0.14^{* *}$ & $-0.16^{\star *}$ & $-0.16^{\star *}$ & $-0.18^{\star *}$ & $-0.2^{\star *}$ \\
\hline & $(0.06)$ & $(0.06)$ & $(0.06)$ & $(0.07)$ & $(0.07)$ & $(0.07)$ & $(0.08)$ \\
\hline \multirow[b]{2}{*}{$a_{31}$} & -0.32 & -0.26 & -0.19 & -0.13 & -0.1 & -0.03 & 0.03 \\
\hline & $(0.21)$ & $(0.21)$ & $(0.21)$ & $(0.21)$ & $(0.22)$ & $(0.23)$ & $(0.24)$ \\
\hline$a_{32}$ & -0.25 & -0.75 & -1.25 & -1.75 & -2 & -2.5 & -3 \\
\hline \multirow[b]{2}{*}{$a_{23}$} & $-0.05^{\star}$ & -0.01 & 0.03 & $0.07^{\star}$ & $0.1^{* *}$ & $0.14^{\star \star}$ & $0.2^{\star \star}$ \\
\hline & $(0.03)$ & $(0.03)$ & $(0.04)$ & $(0.04)$ & $(0.04)$ & $(0.05)$ & $(0.06)$ \\
\hline
\end{tabular}

Source: Prepared by the authors. Notes: 1) Standard errors (se) in parentheses. 2) $* \frac{a_{i j}}{e p\left[a_{i j}\right]}>1.46$; ** $\frac{a_{i j}}{\operatorname{ep}\left[a_{i j}\right]}>1.96 ; \frac{a_{i j}}{\operatorname{ep}\left[a_{i j}\right]}>2.33$.

compatible with various interpretations of the effectiveness of fiscal policy. The larger the (assumed) value of contemporary impact of the economic cycle on government revenues, the larger the contemporary impact of the tax shock will be on its own level of activity. This relationship is identified in both estimates with the two sources of available fiscal data. In Table 3, the asterisks indicate cases in which the ratio between the estimated coefficients $a_{i j}(i, j=1,2,3)$ and their respective standard errors generate estimates which exceed the critical values of the $t$-student table (for large samples).

Very low values for the income-elasticity of government revenues (i.e., $a_{32}$ between -0.75 and -0.25 ) generate counter-intuitive estimates in relation to the instantaneous impact of taxes themselves on GDP: the values of $a_{23}$ in these cases are indicative of an instantaneous positive response of output to tax shocks. Intermediate values of $a_{32}$ are associated with the $a_{23}$ coefficients with the expected sign but, in general, without statistical significance. Only when the elasticity of $a_{32}$ is high-equal or above 2-is the tax impact significant. The values of these various estimates of matrix $\boldsymbol{A}$ will have an impact on their respective impulse-response functions for fiscal shocks.

Figure 2 displays the impulse-response functions for tax shocks [panels (a), 
(a) Impulse = t; Response $=\mathbf{y}$

sample: NT

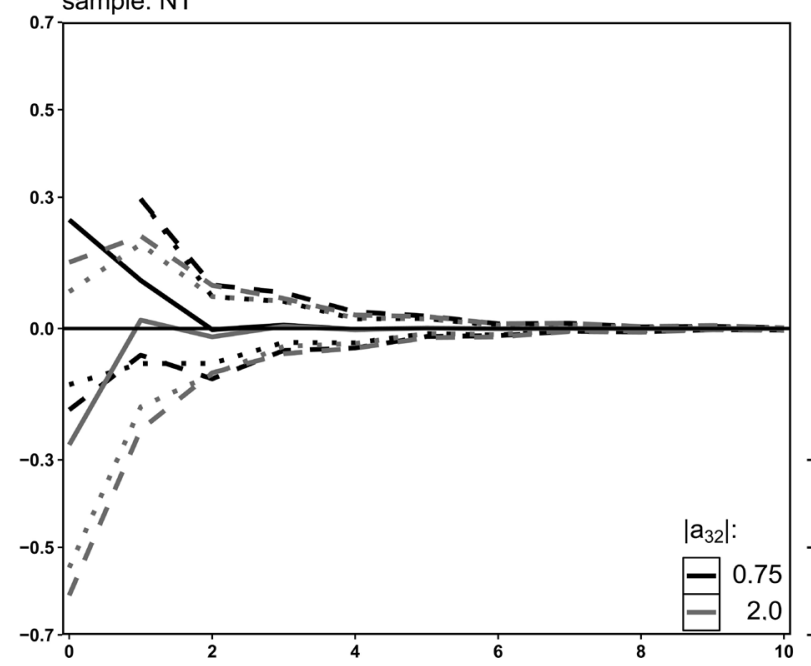

(c) Impulse = t; Response = y

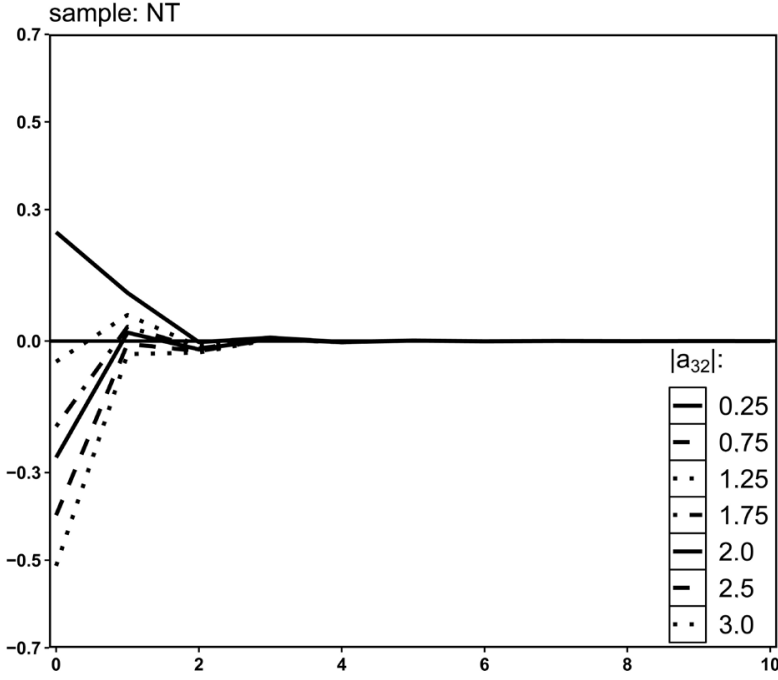

(e) Impulse = g; Response = y

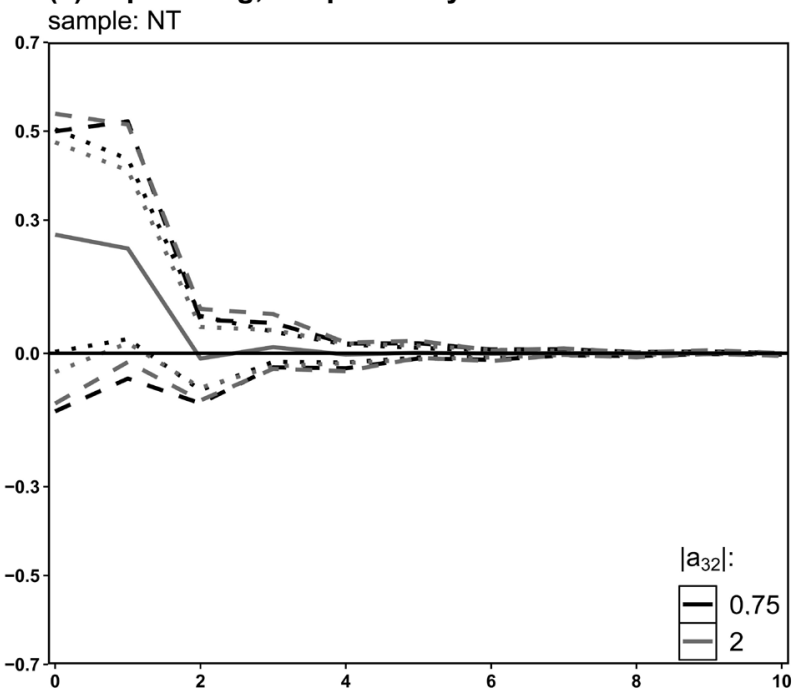

(b) Impulse = t; Response = y

sample: Ipea

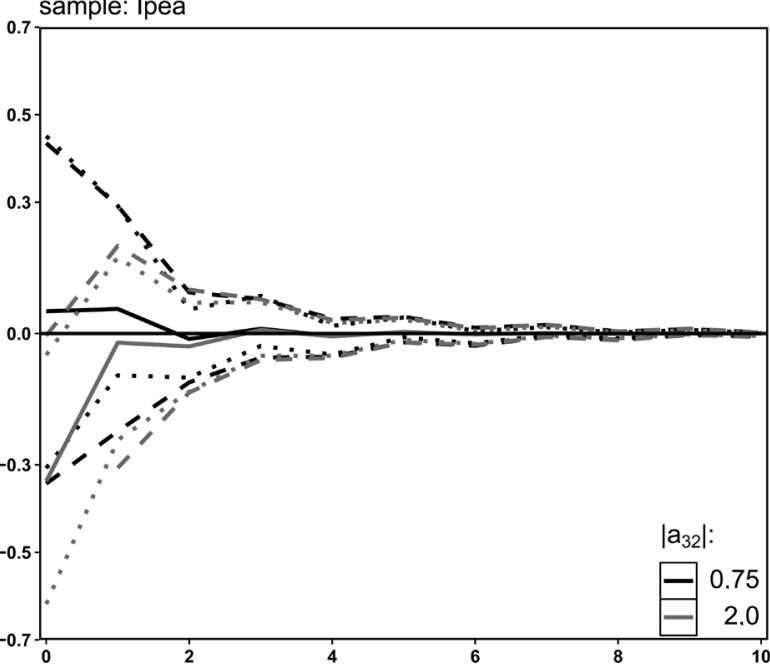

(d) Impulse = t; Response = y

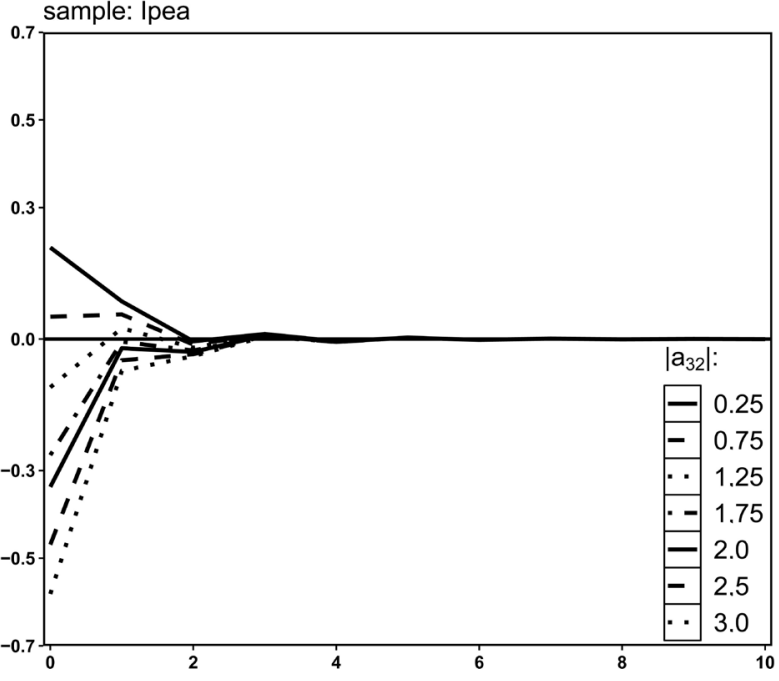

(f) Impulse = g; Response = y

sample: Ipea

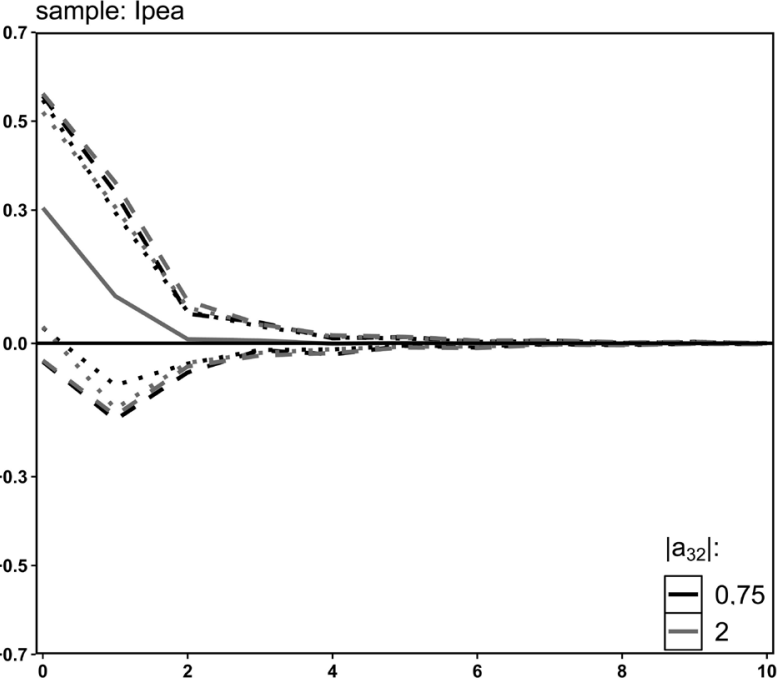

Figure 2. IRFs of fiscal shocks. Source: Prepared by the authors. Notes: 1) Confidence intervals (CI) for a bootstrap of 200 repetitions. 2) Traced lines: CI of 95\%. 3) Line with points: CI of $90 \%$. 
$(b),(c)$ and $(d)$ ] and government spending shocks [panels $(e)$ and $(f)$ ]. The IRFs displayed are the Wold $s$ representations of structural models, which were derived from the first-order reduced-form VAR models, whose estimates produce stationary errors without serial correlations and parameters which guarantee stability. The estimation of the VAR(1) model produces coefficient and regression error estimates, $\boldsymbol{x}_{t}=\hat{\boldsymbol{A}}_{0}+\hat{\boldsymbol{A}}_{1} \boldsymbol{x}_{t-1}+\hat{\boldsymbol{u}}_{t}$. Imposing on the estimates the matrices $\boldsymbol{A}$ and $\overline{\boldsymbol{B}}$, it is possible to recover the structural coefficients, $\boldsymbol{x}_{t}=\hat{\boldsymbol{\Phi}}_{0}+\hat{\boldsymbol{\Phi}}_{1} \boldsymbol{x}_{t-1}+\hat{\boldsymbol{\varepsilon}}_{t}$, with $\hat{\boldsymbol{\Phi}}_{0}=\boldsymbol{A} \hat{\boldsymbol{A}}_{0}, \quad \hat{\boldsymbol{\Phi}}_{1}=\boldsymbol{A} \hat{\boldsymbol{A}}_{1}$ and $\hat{\boldsymbol{\varepsilon}}_{t}=(\overline{\boldsymbol{B}})^{-1} \boldsymbol{A} \hat{\boldsymbol{u}}_{t}$. The solution of the model is given by:

$$
\begin{aligned}
& \boldsymbol{x}_{t}=\hat{\boldsymbol{u}}+\sum_{i=0}^{\infty} \psi_{i} \hat{\boldsymbol{\varepsilon}}_{t-i} \\
& \hat{\boldsymbol{u}}=\hat{\boldsymbol{A}}_{0} /\left(\boldsymbol{I}-\hat{\boldsymbol{A}}_{1}\right) \\
& \hat{\boldsymbol{\psi}}_{i}=\left(\boldsymbol{A}^{-1}\right) \overline{\boldsymbol{B}} \boldsymbol{A}_{1}^{i}
\end{aligned}
$$

in which $\hat{\boldsymbol{\psi}}_{i}=\partial \boldsymbol{x}_{t+i} / \partial \hat{\boldsymbol{\varepsilon}}_{t}$; the terms $\hat{\boldsymbol{\psi}}_{i}(i=1,2, \cdots)$ form the IRF.

Figure 2 displays the output responses $(y)$ to fiscal shocks (in $\tau$ or $g$ ). The panels on the left represent the IRFs using fiscal data from the Treasury, the panels on the right use the fiscal data from Ipea. The panels $(a)$ and $(b)[(e)$ and $(f)]$ exhibit the response of output to the tax [spending] shock, in accordance with the structural models assuming $a_{32}=0.75$ (black) and $a_{32}=2$ (gray). Panels (c) and ( $d$ ) show that there is the aforementioned correlation between the magnitude of output's response to a tax shock and the value of $a_{32}$ : the larger the magnitude of the restricted parameter, the more negative the output's response will be. In the Treasury estimates, the output response is not significant at 10 percent, even when $a_{32}=2$; with the Ipea data, the response is marginally significant at 5 percent for the same restriction. When $a_{32}>2$, the tax shock generates significant GDP responses in both samples. The lower panels of Figure 2 display the responses of output to a shock in government expenses, which are significant at 5 percent (marginally). The sensitivity analysis for $a_{32}$ does not have large effects on output's response to spending shocks. Also, when using the first order model, the impulse-response functions of all the fiscal shocks have little persistence over the long-term and dissipate rapidly.

Table 4 displays the fiscal multipliers calculated based on the IRFs. The values are the result of the interaction between the $\hat{\psi}_{i}$ coefficients and the average values of GDP, and the government's revenues and expenses. In Table 4 the tax multipliers are calculated for the structured models already reported in Table 3 and panels $(c)$ and $(d)$ of Figure 2. In the last column of Table 4 we relate the government spending multipliers just for the structural model $\left|a_{32}\right|=2$. The impact multipliers are on line $t=0$. The other lines exhibit the cumulative multipliers up to $t$ quarters after the initial shock. ${ }^{29}$ By definition, the relationship ${ }^{29}$ The accumulated multiplier for period $t$ is given by the ratio of the present value of the monetary flow implicit in the IRFs of output $(y)$ until period $t$ and the present value of IRFs of the fiscal impulse (either $t$ or $g$ ). The discount for real interest rates during the period from 1997 to 2014 is given by the difference between the basic Selic rate and the inflation rate from Brazilian official consumer price index (IPCA). The Selic and IPCA monthly data can be obtained online through Ipeadata website. 
Table 4. Fiscal multipliers.

\begin{tabular}{|c|c|c|c|c|c|c|c|c|}
\hline \multirow{2}{*}{$t$} & \multicolumn{7}{|c|}{$\tau$} & \multirow{2}{*}{$g^{(1)}$} \\
\hline & $\left|a_{32}\right|=0.25$ & $\left|a_{32}\right|=0.75$ & $\left|a_{32}\right|=1.25$ & $\left|a_{32}\right|=1.75$ & $\left|a_{32}\right|=2$ & $\left|a_{32}\right|=2.5$ & $\left|a_{32}\right|=3$ & \\
\hline \multicolumn{9}{|c|}{ (A) National Treasury } \\
\hline 0 & 0.32 & 0.32 & -0.06 & -0.28 & -0.39 & -0.64 & -0.90 & 0.71 \\
\hline 1 & 0.85 & 0.85 & 0.03 & -0.62 & -1.05 & -2.30 & -4.55 & 1.69 \\
\hline 2 & 0.55 & 0.55 & 0.00 & -0.36 & -0.56 & -1.04 & -1.63 & 1.63 \\
\hline 3 & 0.69 & 0.69 & 0.01 & -0.46 & -0.76 & -1.49 & -2.54 & 1.64 \\
\hline 4 & 0.61 & 0.61 & 0.01 & -0.40 & -0.64 & -1.21 & -1.97 & 1.66 \\
\hline 5 & 0.65 & 0.65 & 0.01 & -0.43 & -0.70 & -1.35 & -2.23 & 1.64 \\
\hline 6 & 0.63 & 0.63 & 0.01 & -0.41 & -0.66 & -1.27 & -2.09 & 1.65 \\
\hline 7 & 0.64 & 0.64 & 0.01 & -0.42 & -0.68 & -1.31 & -2.16 & 1.65 \\
\hline 8 & 0.64 & 0.64 & 0.01 & -0.42 & -0.67 & -1.29 & -2.12 & 1.65 \\
\hline 9 & 0.64 & 0.64 & 0.01 & -0.42 & -0.68 & -1.30 & -2.14 & 1.65 \\
\hline 10 & 0.64 & 0.64 & 0.01 & -0.42 & -0.67 & -1.30 & -2.13 & 1.65 \\
\hline \multicolumn{9}{|c|}{ (B) Ipea } \\
\hline 0 & 0.29 & 0.07 & -0.16 & -0.41 & -0.54 & -0.82 & -1.13 & 0.87 \\
\hline 1 & 0.79 & 0.33 & -0.32 & -1.31 & -2.02 & -4.34 & -10.0 & 1.40 \\
\hline 2 & 0.49 & 0.17 & -0.21 & -0.66 & -0.92 & -1.54 & -2.33 & 1.41 \\
\hline 3 & 0.64 & 0.25 & -0.26 & -0.93 & -1.36 & -2.51 & -4.33 & 1.42 \\
\hline 4 & 0.54 & 0.20 & -0.23 & -0.76 & -1.07 & -1.86 & -2.93 & 1.43 \\
\hline 5 & 0.60 & 0.22 & -0.24 & -0.85 & -1.22 & -2.19 & -3.60 & 1.42 \\
\hline 6 & 0.57 & 0.21 & -0.23 & -0.79 & -1.13 & -1.98 & -3.18 & 1.43 \\
\hline 7 & 0.58 & 0.22 & -0.24 & -0.82 & -1.18 & -2.09 & -3.41 & 1.42 \\
\hline 8 & 0.57 & 0.21 & -0.23 & -0.81 & -1.15 & -2.03 & -3.27 & 1.42 \\
\hline 9 & 0.58 & 0.22 & -0.24 & -0.82 & -1.17 & -2.07 & -3.35 & 1.42 \\
\hline 10 & 0.57 & 0.21 & -0.24 & -0.81 & -1.16 & -2.05 & -3.31 & 1.42 \\
\hline
\end{tabular}

Source: Prepared by the authors. Note: The spending multiplier is in accordance with the structural model $\left|a_{32}\right|=2$.

found between parameter $a_{32}$ and $a_{23}$ is extended to tax multipliers: for both the impact of the fiscal shock as well as the cumulative shock, the multiplier will be greater (in magnitude) the larger the sensitivity to government revenues in the economic cycle. When $a_{32}>2$, the tax multiplier tends to approximate the spending multiplier and may surpass it (in magnitude) depending on the fiscal data sample used.

The question of which fiscal instrument is the most effective (i.e., its ability to affect output in the short term) is present, in one form or another, in almost all empirical works that measure multipliers. The conclusion of Blanchard and Perotti [13] is that [for the United States] spending is more effective than taxes in 
shifting aggregate demand and output. The opposite conclusion was drawn by Mountford and Uhlig [29] — using the same database as BP [13] by different identification methodology. This study shows that even within SVAR methodology, for the Brazilian economy at least, the answer to this controversy depends on basic assumptions about tax revenues summarizes in the structural matrix of the model. ${ }^{30}$ In the structural VAR model the central question should be: what should be the value chosen for the parameters of income-elasticity of tax revenues? To the authors of this study the evidence so far points to a large value, probably between 2 and 2.5. This being the case, one can argue that Brazilian tax multiplier is of the same order of magnitude as the spending multiplier; that is, there isn't a single fiscal instrument unequivocally more efficient than the other. If $\left|a_{32}\right|$ is in fact between 2 and 2.5, the instantaneous tax multiplier is estimated between $-\$ 0.4$ and $-\$ 0.8$; the cumulative multiplier attaining values between $-\$ 0.7$ and $-\$ 2$ in 10 months. When $\left|a_{32}\right|=2$, the Treasury sample implies tax multiplier lower than the spending multiplier; the Ipea sample would suggest the opposite.

Table 4 summarizes the results of this article. Spending multipliers tends slightly lower than unit at impact. These results are in line with government's consumption multipliers estimated by Pires [14] and Castelo-Branco et al. [16]; and well above those calculated by Peres e Ellery [12], Mendonça et al. [17] and Oreng [11]. The long run multipliers (10 quarters) tend to be well above unit. The impact multipliers carry more confidence since the impulse-response functions tend to be statistically significant at the impact and at most on next period. The same is true for tax multipliers. More importantly, the tax multipliers-the focus of this study-are shown to be substantial when income-elasticity of government revenues are high. Assuming $\left|a_{32}\right|=2.5$, the impact tax multiplier is well above calculation from other studies in the Brazilian literature reviewed by the authors. In fact, the results found here puts tax policy at least as equally effective as spending policy. ${ }^{31}$

All in all, the results found and summarized in Table 4 attest to the importance of a precise estimation of the key-parameter of the structural VAR fiscal policy models in Brazil: the income-elasticity of tax revenues. Later studies can, and should, refine the discussion above with updated estimated of the key-parameters. In addition, one can argue that the focus on the income-elasticity of tax revenues raised another dispute: about the level and composition of the tax burden. Surely the characteristics of the tax burden will have impacts on the aforementioned parameter through the effects on the marginal tax burden. In recent decades, for ${ }^{30}$ Caldara and Kamps [30] try to reconciliate the apparently divergent results between the SVAR methodology and the sign restriction approach (US data). Both methodologies can arrive at similar results, depending on the restrictions made on the structural matrix of the SVAR model. In other words, there is a SVAR identification which can be compatible with the results of other approaches. The work of Caldara and Kamps is, in part, a test of sensitivity which is analogous to the present study.

${ }^{31}$ The complementary material referred earlier also brings summary tables of the relevant empirical literature of fiscal policy in Brazil. 
example, there has been a strong rise in Brazilian total tax burden: going from values close to $23 \%$ of GDP (at the end of the 1980s) to roughly $35 \%$ at the beginning of the current decade [31]. At the same time, there is evidence that the tax burden general trend has been relatively more pronounced on those in the lower income brackets [32]. Combined, these trends (level and distribution of the tax burden) can have important impacts on the marginal tax burden-which must have influence on the magnitude of the tax multiplier. It can be argued that the marginal tax burden will suffer even further alterations when (and if) - to the extent that the country displays sustained economic growth-significant portions of the population change their income levels and possibly their average tax burden (considering no tax reform). Those questions do not have a categorical response at this point, and should encourage new discussion of the Brazilian tax system and its effects on the effectiveness of fiscal policy. In sum, the debate about the tax burden is not just whether it is high or low, according to some criterion (e.g., distortions, incentives, income distribution, etc.), but also whether the arrangement has some impact on the ability of the government to promote effective measures to stabilize output.

\section{Conclusions}

This study presents measures of the effects of fiscal shocks on Brazil's GDP - with focusing on tax shocks and assuming different hypotheses of identification in the SVAR model. The hypotheses are related to the value of the instantaneous elasticity of government revenues in relation to output. The estimations used quarterly data from 1997:1 to 2014:3 and two sets of fiscal variables: the official data from National Treasury (with adjustments) and an alternative database detailed in Gobetti and Orair [1], correcting problems and distortions within the official database (including the extra-budgetary operations that distorted primary surplus for some years).

The value of the instantaneous sensitivity of government revenues in relation to output is the key parameter used to determine the tax multiplier. There is a correlation between this parameter and the instantaneous effect of taxes on the level of activity itself, attested by the estimates of the contemporary correlation matrices (i.e., the structural matrices) of the SVAR models. When the income-elasticity of taxes is high, there is a tendency to the tax-elasticity of output also to be high. This latter elasticity defines, to a great extent, the initial dynamic of the output response to tax shocks.

In qualitative terms, these results are in line with most of the applied studies in Brazil. The fiscal shocks generate traditional Keynesian effects: the level of activity grows by virtue of a government spending shock and decreases by virtue of shocks in government revenues. However, the focus of this study is the relationship between the magnitude of the response of economic activity (to the tax shock) and the hypotheses regarding the parameter which measure the income-elasticity of government revenues. The values assumed for this elasticity 
parameter vary from a floor of $0.25 \%$ to a maximum of $3 \%$. This interval encompasses the values used in other studies in Brazilian literature. When the SVAR model is identified with a low value for this referenced elasticity, the tax shocks generate output responses that are not significant; when the elasticity is large (above 2\%), tax shocks cause negative and significant output responses that are stronger (in absolute value) than those found by other studies.

As a rule, (tax and spending) impact multipliers are below one. The exception occurs when the income-elasticity of tax revenues is equal to $3 \%$ in one of the fiscal series. In the extreme case the cumulative tax multiplier ten months after the shock reaches a value above $-\$ 3$. When more modest hypotheses are adopted (i.e., an output-elasticity of revenues between 2 and 2.5), the tax (impact) multipliers remains within the range of $-\$ 0.4$ and $-\$ 0.8$. The spending multiplier, in turn, remains between $\$ 0.7$ and $\$ 0.9$. After 10 periods, the cumulative had substantial increase. Even though these should be interpreted with care-impulse-response functions are largely statistically insignificant after the first period beyond the initial shock-, one should note that, still with modest hypothesis of output-elasticity of taxes, tax multipliers and spending multipliers can reach $-\$ 2$ and $-\$ 1.6$, respectively.

\section{Conflicts of Interest}

The authors declare no conflicts of interest regarding the publication of this paper.

\section{References}

[1] Gobetti, S.W. and Orair, R.O. (2017) Resultado primário e contabilidade criativa: Reconstruindo as estatísticas fiscais "acima da linha" do governo central. Texto para discussão Ipea, n. 2288.

[2] Ilzetzki, E., Mendoza, E.G. and Végh, C.A. (2013) How Big (Small?) Are Fiscal Multipliers? Journal of Monetary Economics, 60, 239-254. https://doi.org/10.1016/j.jmoneco.2012.10.011

[3] Favero, C. and Giavazzi, F. (2007) Debt and the Effects of Fiscal Policy. NBER Working Paper No. 12822. https://doi.org/10.3386/w12822

[4] Auerbach, A.J. and Gorodnichenko, Y. (2012) Measuring the Output Responses to Fiscal Policy. American Economic Journal: Economic Policy, 4, 1-27. https://doi.org/10.1257/pol.4.2.1

[5] Blanchard, O. and Leigh, D. (2013) Growth Forecast Errors and Fiscal Multipliers. American Economic Review: Papers \& Proceedings, 103, 117-120. https://doi.org/10.1257/aer.103.3.117

[6] Riera-Crichton, D., Vegh, C.A. and Vuletin, G. (2014) Procyclical and Countercyclical Fiscal Multipliers: Evidence from OECD Countries. NBER Working Paper No. 20533. https://doi.org/10.3386/w20533

[7] Cavalcanti, A.F.H. (2009) Política fiscal e nível de atividade: Breve resenha da literatura empírica para o Brasil. Economia \& Tecnologia, 19, 15-24. https://doi.org/10.5380/ret.v5i4.27099

[8] Cavalcanti, A.F.H. and Silva, N.L.C. (2010) Dívida pública, política fiscal e nível de 
atividade: Uma abordagem VAR para o Brasil no período 1995-2008. Economia Aplicada, 14, 391-418.

[9] Mendonça, M.J., Medrano, L.A. and Sachsida, A. (2009) Avaliando efeitos da política fiscal no Brasil: Resultados de um procedimento de identificação agnóstica. Texto para discussão Ipea, n. 1377.

[10] Pires, M.C.C. (2012) Controvérsias recentes sobre multiplicadores fiscais no Brasil. $\mathrm{V}$ Encontro Internaiconal da AKB.

[11] Oreng, M. (2012) Estimando o impacto da política fiscal no Brasil: 2004 a 2011. FGV Working Paper No. 433.

[12] Peres, M.A.F. and Ellery Jr., R. (2009) Efeitos dinâmicos dos choques fiscais do governo central no PIB do Brasil. Pesquisa e Planejamento Econômico, 39, 159-206.

[13] Blanchard, O. and Perotti, R. (2002) An Empirical Characterization of the Dynamic Effects of Changes in Government Spending and Taxes on Output. The Quarterly Journal of Economics, 117, 1329-1368. https://doi.org/10.1162/003355302320935043

[14] Pires, M.C.C. (2014) Política fiscal e ciclos econômicos no Brasil. Economia Aplicada, 18, 69-90. https://doi.org/10.1590/1413-8050/ea350

[15] Matheson, T. and Pereira, J. (2016) Fiscal Multipliers for Brazil. IMF Working Paper. https://doi.org/10.5089/9781484307892.001

[16] Castelo-Branco, M.A., Lima, E.C.R. and Paula, L.F. (2017) Mudanças de regime e multiplicadores fiscais no Brasil em 1999-2012: Uma avaliação empírica com o uso da metodologia MS-SBVAR. Pesquisa e Planejamento Econômico, 47, 7-62.

[17] Mendonça, D.P., Marçal, E. and Holland, M. (2016) Is Fiscal Policy Effective in Brazil? An Empirical Analysis. FGV Working Paper No. 433.

[18] Enders, W. (2015) Applied Econometric Time Series. 4th Edition, Wiley \& Sons, New York.

[19] Lütkepohl, H. and Krätzig, M. (2004) Applied Time Series Econometrics. Cambridge University Press, Cambridge. https://doi.org/10.1017/CBO9780511606885

[20] Lütkepohl, H. (2006) New Introduction to Multiple Time Series Econometrics. Springer, Berlin. https://doi.org/10.1007/978-3-540-27752-1

[21] Peres, M.A.F. (2006) Efeitos dinâmicos da política fiscal sobre o nível de atividade econômica: Um estudo para o caso brasileiro. Dissertação (mestrado em economia), Departamento de Economia, Universidade de Brasília, Brasília.

[22] Ilzetzki, E. (2011) Fiscal Policy and Debt Dynamics in Developing Countries. World Bank Working Paper No. 5666. https://doi.org/10.1596/1813-9450-5666

[23] Perotti, R. (2004) Estimating the Effects of Fiscal Policy in OECD Countries. IGIER Working Paper. https://doi.org/10.2139/ssrn.637189

[24] Santos, C.H.M., Silva, A.C.M. and Ribeiro, M.B. (2010) Uma metodologia de estimação da carga tributária líquida brasileira trimestral no período 1995-2009. Revista de Economia Contemporânea, 14, 209-236. https://doi.org/10.1590/S1415-98482010000200001

[25] Santos, C.H.M., Orair, R.O., Gobetti, S.W., Ferreira, A.S., Rocha, W.S., Da Silva, H.L. and Britto, J.M. (2012) Estimativas mensais da formação bruta de capital fixo no Brasil (2002-2010). Economia Aplicada, 16, 445-473. https://doi.org/10.1590/S1413-80502012000300005

[26] Grudtner, V. and Aragon, E.B. (2017) Multiplicador dos gastos do governo em períodos de expansão e recessão: Evidências empíricas para o Brasil. Revista Brasi- 
leira de Economia, 71, 321-345. https://doi.org/10.5935/0034-7140.20170015

[27] Zivot, E. and Andrews, D.W.K. (1992) Further Evidence on the Great Crash, the Oil-Price Shock and the Unit-Root Hyphotesis. Journal of Business \& Economic Statistics, 10, 251-270. https://doi.org/10.1080/07350015.1992.10509904

[28] Ramey, V.A. and Shapiro, M.D. (1998) Costly Capital Reallocation and the Effects of Government Spending. Carnegie-Rochester Conference Series on Public Policy, 48, 145-194. https://doi.org/10.1016/S0167-2231(98)00020-7

[29] Mountford, A. and Uhlig, H. (2008) What Are the Effects of Fiscal Policy Shocks? Journal of Applied Econometrics, 24, 960-992. https://doi.org/10.1002/jae.1079

[30] Caldara, D. and Kamps, C. (2008) What Are the Effects of Fiscal Policy Shocks? A VAR-Based Comparative Analysis. ECB Working Paper Series No. 877.

[31] Orair, R.O., Gobetti, S.W., Leal, É.M. and Silva, W.J. (2013) Carga tributária brasileira: Estimação e análise dos determinantes da evolução recente. Texto de discussão do Ipea, n. 1875.

[32] Ribeiro, M.B. (2010) Uma análise da carga tributária bruta e das transferências de assistência e previdência no Brasil, no período 1996-2009: Evolução, composição e suas relações com a regressividade e a distribuição de renda. Texto de discussão do Ipea, n. 1464. 